\title{
Analysis of Humidity Halos around Trade Wind Cumulus Clouds
}

\author{
Miao-Ling Lu,* Jian Wang, ${ }^{*} @$ Andrew Freedman, ${ }^{+}$Haflidi H. Jonsson, ${ }^{\#}$ Richard C. Flagan,* \\ Robert A. McClatchey, ${ }^{+}$and John H. SeINFeld* \\ *California Institute of Technology, Pasadena, California \\ ${ }^{+}$Aerodyne Research, Inc., Billerica, Massachusetts

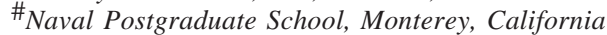

(Manuscript received 17 June 2002, in final form 12 November 2002)

ABSTRACT

\begin{abstract}
Regions of enhanced humidity in the vicinity of cumulus clouds, so-called cloud halos, reflect features of cloud evolution, exert radiative effects, and may serve as a locus for new particle formation. Reported here are the results of an aircraft sampling campaign carried out near Oahu, Hawaii, from 31 July through 10 August 2001, aimed at characterizing the properties of trade wind cumulus cloud halos. An Aerodyne Research, Inc., fast spectroscopic water vapor sensor, flown for the first time in this campaign, allowed characterization of humidity properties at $10-\mathrm{m}$ spatial resolution. Statistical properties of 60 traverses through cloud halos over the campaign were in general agreement with measurements reported by Perry and Hobbs. One particularly long-lived cloud is analyzed in detail, through both airborne measurement and numerical simulation, to track evolution of the cloud halos over the cloud's lifetime. Results of both observation and the simulation show that cloud halos tend to be broad at lower levels and narrow at upper levels, and broader on the downshear side than on the upshear side, broadening with time particularly in the downshear direction. The high correlation of clear-air turbulence distribution with the halo distribution temporally and spatially suggests that the halo forms, in part, due to turbulent mixing at the cloud boundary. Radiative calculations carried out on the simulated cloud and halo field indicate that the halo radiative effect is largest near cloud top during mature and dissipation stages. The halo-enhanced atmospheric shortwave absorption, averaged over this period, is about $1.3 \%$ of total solar absorption in the column.
\end{abstract}

\section{Introduction}

Cloud halos, which are regions of enhanced humidity in the vicinity of isolated cumulus clouds, are intimately associated with atmospheric dynamics, as they reflect features of cloud formation and dissipation, and might also serve as the predominant region of cloud-associated new particle formation. Moreover, halos exert radiative effects, in addition to those of the clouds themselves, which have an impact on the energy balance of the atmosphere. Halos have been identified in aircraft studies (Malkus 1949; Ackerman 1958; Telford and Wagner 1980; Radke and Hobbs 1991; Hobbs and Radke 1992; Perry and Hobbs 1996), ground-based measurements (Platt and Gambling 1971; Kollias et al. 2001), modeling studies of detrainment (Raymond and Blyth 1986; Bretherton and Smolarkiewicz 1989; Raga et al. 1990; Taylor and Baker 1991), and numerical simulations (Lu

@ Current affiliation: Environmental Sciences Department, Brookhaven National Laboratory, Upton, New York.

Corresponding author address: Dr. John H. Seinfeld, California Institute of Technology, 210-41, Pasadena, CA 91125.

E-mail: seinfeld@caltech.edu et al. 2002). Such regions have been also reported associated with frontal clouds (Weber et al. 2001) and mountain thunderstorms (Raymond et al. 1991). Summaries of these airborne and ground-based measurements of cloud halos are given in Table 1 .

From aircraft measurements of 31 small to medium sized, isolated marine cumulus clouds off the coast of Washington and Oregon, Perry and Hobbs (1996) identified three factors dominant in determining the existence and extent of halos-cloud age, wind shear, and presence of a stable atmospheric layer. The halo region was found to broaden with increasing cloud age, with the region being most significant in the downshear direction from the cloud (see section 3a for definition of upshear and downshear).

Lu et al. (2002) utilized the three-dimensional (3D) Regional Atmospheric Modeling System (RAMS) model to simulate the spatial and temporal development of cloud halos for isolated, small to medium sized cumulus both in the presence and absence of wind shear. The simulated temporal and spatial patterns were in reasonable quantitative agreement with reported observations. They further calculated the radiative effect of the humidity halo using a 3D radiative transfer model. Through case studies, Lu et al. (2002) found that halos 
TABLE 1. Airborne and ground-based measurements of cloud halos.

\begin{tabular}{|c|c|c|c|}
\hline & Cloud & Location & Halo observations \\
\hline Malkus (1949) & Trade cumulus & Caribbean Sea & $\begin{array}{l}\text { Clear-air disturbance was } \\
\text { found generally in the } \\
\text { downshear from the cloud, } \\
\text { broader on the downshear } \\
\text { than the upshear side. This } \\
\text { clear-air disturbance was lat- } \\
\text { er related to the humidity } \\
\text { halo by Ackerman }\end{array}$ \\
\hline Ackerman (1958) & Trade cumulus & Caribbean Sea & $\begin{array}{l}\text { The major regions of clear-air } \\
\text { disturbance (e.g., water va- } \\
\text { por field) was found on the } \\
\text { downshear side of the cloud } \\
\text { and broadens as cloud ages }\end{array}$ \\
\hline $\begin{array}{l}\text { Telford and Wagner } \\
\text { (1980) }\end{array}$ & Small cumulus & $\begin{array}{l}\text { Off the northeast shoreline of } \\
\text { Chesapeake Bay }\end{array}$ & $\begin{array}{l}\text { Clear-air disturbance in water } \\
\text { vapor mixing ratio was only } \\
\text { on the dissipating (down- } \\
\text { shear) side of the cloud }\end{array}$ \\
\hline $\begin{array}{l}\text { Radke and Hobbs } \\
\text { (1991) }\end{array}$ & Small cumulus & $\begin{array}{l}\text { East of the Cascade Mts., } \\
\text { Washington }\end{array}$ & $\begin{array}{l}\text { High humidity and Aitken nu- } \\
\text { cleus concentration in clear- } \\
\text { air regions near cloud ex- } \\
\text { tended out to distances of } \\
\text { several cloud radii }\end{array}$ \\
\hline Raymond et al. (1991) & Moutain thunderstorm & New Mexico & $\begin{array}{l}\text { Layers of elevated humidity } \\
\text { were visible as detraining } \\
\text { stratus clouds }\end{array}$ \\
\hline $\begin{array}{l}\text { Hobbs and Radke } \\
\text { (1992) }\end{array}$ & Small cumulus & $\begin{array}{l}\text { East of the Cascade Mts., } \\
\text { Washington }\end{array}$ & $\begin{array}{l}\text { Elevated humidity and Aitken } \\
\text { nuclei in the vicinity of } \\
\text { cloud at the cross-shear di- } \\
\text { rection }\end{array}$ \\
\hline $\begin{array}{l}\text { Perry and Hobbs } \\
\quad(1996)\end{array}$ & Small-medium sized cumulus & $\begin{array}{l}\text { Off the coast of Washington } \\
\text { and Oregon }\end{array}$ & $\begin{array}{l}\text { First statistical analysis of } \\
\text { cloud halos }\end{array}$ \\
\hline Kollias et al. (2001) & Marine fair weather cumuli & Virginia Key, Miami, Florida & $\begin{array}{l}\text { Large moisture gradients were } \\
\text { observed at the cloud later- } \\
\text { als by radar wind profiler }\end{array}$ \\
\hline Weber et al. (2001) & Frontal clouds & $\begin{array}{l}\text { Remote South Pacific Ocean } \\
\qquad\left(47^{\circ} \mathrm{S}, 153^{\circ} \mathrm{E}\right)\end{array}$ & $\begin{array}{c}\text { Gradual decrease in } \mathrm{RH}(3 \% \\
\left.\mathrm{km}^{-1}\right) \text { beyond the cloud } \\
\text { boundary was identified }\end{array}$ \\
\hline
\end{tabular}

exert their greatest radiative effect for more convective clouds with vertical wind shear in the dissipation stage of cloud lifetime.

A number of investigators (e.g., Weber et al. 2001; Clarke and Kapustin 2002) have reported new particle formation in the vicinity of clouds. Kerminen and Wexler (1994) showed that atmospheric nucleation is most favored when there is a rapid transition from moderate to high humidity. Perry and Hobbs (1994) observed elevated ambient condensation nuclei $(\mathrm{CN})$ levels associated with conditions of high humidity, low total aerosol surface area, low temperature, high $\mathrm{SO}_{2}$, and enhanced actinic flux. Their observations indicate that clear air above cloud top and downwind of the cloud in the outflow anvil are possible loci for new particle formation.

We report here on an aircraft sampling campaign, termed "Cloud Halo," conducted between 31 July and 10 August 2001 in the vicinity of Oahu, Hawaii. Our goals are to investigate cloud halos using a new, fastresponse water vapor sensor as a follow-on to earlier studies, to evaluate the ability to simulate halo development with a 3D dynamical model (RAMS), and to evaluate the radiative effects of cloud halos. The measurements from this campaign add to the existing body of information on cloud halos, their frequency of occurrence, spatial extent, and meteorological characteristics. These data will aid in assessing the shortwave (SW) radiative impact of halo regions and the extent to which halo regions are of importance in the SW energy balance of the atmosphere. Radiative flux measurements in the vicinity of cloud edges are difficult to interpret. When numerical simulation of cloud development can be demonstrated to agree qualitatively with observations, then numerically simulated halo fields can be used as a basis to assess radiative impacts.

In section 2 the sampling campaign and the airborne instruments employed are described. We then select for detailed analysis one cloud sampled during the campaign for which an extraordinary degree of observation was achieved (section 3). A numerical simulation of the development of that particular cloud is presented in section 4 . In section 5 , we simulate the radiative properties of halos and the extent to which halos influence overall atmospheric SW absorption. 


\section{Cloud Halo field experiment and instrumentation}

In the Cloud Halo campaign, the Center for Interdisciplinary Remotely-Piloted Aircraft Studies (CIRPAS) Twin Otter aircraft flew nine missions out of Marine Corps Base Hawaii at Kaneohe, Oahu, Hawaii $\left(21.44^{\circ} \mathrm{N}\right.$, $157.77^{\circ} \mathrm{W}$ ) from 31 July through 10 August 2001. Ambient conditions northeast of Kaneohe Bay, Hawaii, are typical of those giving rise to trade wind cumulus (Austin et al. 1996). Forty-four isolated cumulus clouds were sampled over the nine missions. The Twin Otter aircraft executed a similar flight pattern for each cloud, sampling at a near constant aircraft velocity of $50 \mathrm{~m} \mathrm{~s}^{-1}$, starting over the cloud top, followed by horizontal traverses through the cloud at ever decreasing altitudes, ending with a traverse just below the cloud. The horizontal passes through a given cloud, chosen to be in the upwind and downwind directions, commenced at least $3 \mathrm{~km}$ from the visible cloud boundary. Ambient soundings in clear air were usually taken each day at the beginning and the end of the mission.

The meteorological instrument package on the Twin Otter consisted of a Rosemount E102AL total temperature probe, Setra 270 static pressure transducer, and Setra 239 differential pressure transducers for measurements of dynamic pressure, side slip, and angle of attack. The Rosemount total temperature probe uses a sensing element in the airstream to measure the temperature. The accuracy of this instrument has been reported in Lawson and Cooper (1990) to be $0.3^{\circ} \mathrm{C}$ in clear sky and $-1^{\circ} \mathrm{C}$ at a liquid water content (LWC) of $2 \mathrm{~g} \mathrm{~m}^{-3}$. A NovAtel Propack GPS system reported location as well as ground speed, track, and vertical speed. The Trimble Advanced Navigation System (TANS) vector provided the aircraft attitude in addition to a redundant measurement of location. Humidity measurements were carried out by a new high-speed $(10-\mathrm{Hz}$ bandwidth) spectroscopic water vapor concentration monitor developed by Aerodyne Research, Inc. (described in more detail below) and an Edgetech 137-C3 chilled mirror dewpoint probe.

Cloud LWC was measured by the cloud/aerosol precipitation spectrometer (CAPS) probe manufactured by Droplet Measurement Technologies, Inc. It contains a cloud and aerosol spectrometer (CAS; measuring particle diameters from $0.5-50 \mu \mathrm{m})$ and a cloud imaging probe (CIP; measuring particle diameters from 25-1550 $\mu \mathrm{m})$. The CAS collects both forward $\left(2^{\circ}-12^{\circ}\right)$ and backward $\left(168^{\circ}-178^{\circ}\right)$ scattered light from particles passing through a focused laser beam and sorts the measured pulse heights into 20 channels, each of which corresponds to a particle diameter. The CIP measures particle images by capturing the shadow of the particles that pass through a focused laser. The collimated beam illuminates a linear array of 64 photodiodes. The array is scanned at a rate corresponding to $25 \mu \mathrm{m}$ of distance traveled, which thus determines the resolution of the probe.

A differential mobility analyzer (DMA) system in the main cabin was used to measure aerosol size distributions from 10 to $350-\mathrm{nm}$ diameter. The aerosol sample was drawn from the community inlet that was shared by other instruments in the main cabin. For the particle size range measured by the DMA system, the transmission efficiency of aerosol through the community inlet has been established to be essentially $100 \%$. The aerosol sample flowed first to a Nafion drier (PermaPure PD07018T-12SS), in which the relative humidity of the sample was reduced to below $27 \%$. The charging distribution of the dried aerosol was then brought to a known steady state by a ${ }^{210} \mathrm{Po}$ charger. Nearly monodisperse aerosols were selected by a cylindrical differential mobility analyzer (CDMA; TSI Inc., model 3081) and counted by a condensation nucleus counter (CNC; TSI Inc., model 3010), which has a 50\% counting efficiency at 10-nm diameter. The CDMA was operated with an aerosol to sheath flow ratio of $0.604 \mathrm{~L} \mathrm{~min}^{-1}$ to $6.04 \mathrm{~L} \mathrm{~min}^{-1}$. All flows were monitored and maintained by feedback controllers to compensate for environmental changes during airborne measurement. Using the scanning mobility technique (Wang and Flagan 1990), the DMA system generates a complete size distribution over the range of 10- to 350-nm diameter every $50 \mathrm{~s}$. The DMA system was calibrated prior to the Cloud Halo experiment and accurately recovered both the peak size and number concentration of monodisperse calibration aerosols down to $15-\mathrm{nm}$ diameter. Data from the DMA system were analyzed using the data inversion procedure described by Collins et al. (2002).

In addition to the DMA system, a Particle Measuring Systems, Inc. (PMS) passive cavity aerosol spectrometer probe (PCASP)-100X and a PMS forward scattering spectrometer probe (FSSP)-100 were deployed. The two PMS optical probes were mounted under the left wing of the Twin Otter aircraft. Since a heater on the inlet of the PCASP reduced the relative humidity to below $30 \%$, the PCASP provided measurements of dry aerosol size distributions. The PCASP has a measurement range of $0.1-3.5 \mu \mathrm{m}$ in diameter and was calibrated using polystyrene latex spheres of known sizes. Since the PCASP infers particle size from light scattered by the particle, the bin size of the PCASP was adjusted for measurement of dry marine aerosol, using the procedure of Liu and Daum (2000). The FSSP provided cloud droplet size distributions from 2.9- to $40-\mu \mathrm{m}$ diameter during the experiment. The FSSP was calibrated with spherical glass beads, and the bin sizes were adjusted for the refractive index of cloud droplets through Mie calculations. Three condensation nucleus counters were operated in parallel. One of them is an ultrafine condensation nucleus counter (UCNC, TSI model 3025), which measures the total concentration of particles larger than 3-nm diameter. The other two are condensation nucleus counters (TSI model 3010) that report the total concen- 


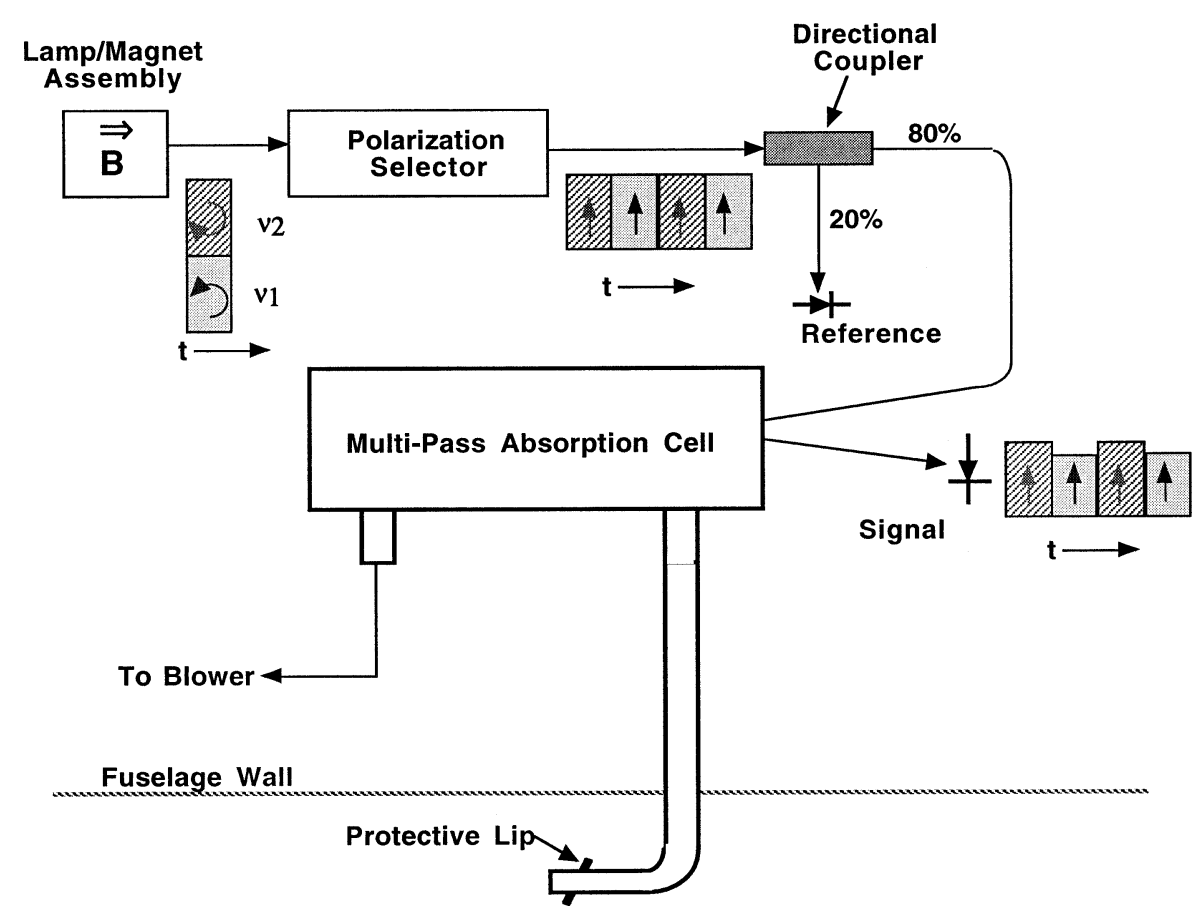

FIG. 1. Schematic of the Aerodyne Research, Inc., spectroscopic water vapor sensor. Also shown are the relative intensities of the frequency components produced by the Zeeman (magnetic) splitting of the lamp output. The lower frequency component $\nu 1$ is absorbed by the water vapor in the absorption cell, producing a net AC signal at the detector. See text for a full explanation.

trations of particles larger than 6- and 10-nm diameter, respectively.

The Aerodyne Research, Inc., fast spectroscopic water vapor sensor (Kebabian et al. 2002) was employed for the first time in field measurements in the present study. The instrument operates by measuring the differential absorption of emission lines emanating from a simple argon gas discharge lamp in a water vapor absorption band in the near infrared ( $\sim 935 \mathrm{~nm}$; Kebabian 1998; Kebabian et al. 1998, 2002). The lamp emission of interest is the neutral argon line at a frequency of 10 $687.43 \mathrm{~cm}^{-1}$ (Moore 1971; Kaufman and Edlen 1974). This line is close to, but not coincident with, a strong water vapor absorption line at $10687.36 \mathrm{~cm}^{-1}$ (Rothman et al. 1998). A longitudinal magnetic field of the proper strength (the Zeeman effect; Jenkins and White 1957), is used to divide the lamp emission into one frequency component (at lower energy $\nu 1$ ) that is strongly absorbed by the water vapor line, and a second frequency component (at higher energy $\nu 2$ ) that is only weakly absorbed. This fact forms the basis for a differential absorption measurement.

Referring to a schematic diagram of the sensor shown in Fig. 1, the argon discharge lamp, in the presence of the magnetic field, produces two components with equal intensity, but orthogonal circular polarizations. Discrimination between the two frequency components is accomplished by using polarization selection. The polarization selector produces a linearly polarized light beam of half the intensity and comprising alternate frequency components. When this light passes through an multipass absorption cell of off-axis astigmatic design (McManus et al. 1995) containing air with finite humidity, the lower frequency component $\nu 1$ is more strongly absorbed than the other component. The resulting modulated signal $(\Delta I$ $\left.=I_{\nu 2}-I_{\nu 1}\right)$ can be measured using synchronous detection techniques and compared to the average DC signal level $\left[I_{0}=\left(I_{\nu 1}+I_{\nu 2}\right) / 2\right]$ to provide an absorbance measurement $\left(\Delta I / I_{0}\right)$. A full description of the sensor and a comparison of its performance to a chilled mirror hygrometer and capacitance-based polymer sensor during the flight are presented in Kebabian et al. (2002).

As shown in Fig. 1, air was drawn into the sensor through a stainless steel tube $(2.5 \mathrm{~cm}$ outside diameter $)$ that extended past the boundary layer of the aircraft and was positioned so that clean air was being sampled. In order to minimize water droplet intake, the tube inlet faced backward and had a protective lip welded onto it in order to prevent intake of liquid water that had condensed on the outside of the intake tube. No discernible uptake of liquid water was noted in approximately 40 $\mathrm{h}$ of flight time. Upon entry into the fuselage cabin, the air flowed through a resistive heater in order to prevent any condensation in the polyethylene tubing that transported the air to the sensor. A $15 \mathrm{~L} \mathrm{~s}^{-1}$ blower, located at the exit of the sensor, was used to maintain the air volume flow at $\sim 10 \mathrm{~L} \mathrm{~s}^{-1}$. The air was then exhausted into the cabin. The sensor was operated at an electronic 
TABLE 2. Characteristics of nine trade wind cumulus clouds studied

\begin{tabular}{|c|c|c|c|c|c|c|}
\hline Cloud no. & Cloud & Top (m) & Base (m) & Depth (m) & $\begin{array}{c}\text { Average } \\
\text { width* }(\mathrm{km})\end{array}$ & Traverses \\
\hline 1 & 3 Aug cloud 3 & 1925 & 457 & 1468 & 1.15 & 4 \\
\hline 2 & 6 Aug cloud 1 & 1731 & 488 & 1243 & 6.77 & 5 \\
\hline 3 & 6 Aug cloud 6 & 1782 & 594 & 1188 & 1.53 & 7 \\
\hline 4 & 7 Aug cloud 1 & 2026 & 453 & 1573 & 4.66 & 6 \\
\hline 5 & 7 Aug cloud 5 & 1970 & 568 & 1402 & 2.05 & 6 \\
\hline 6 & 7 Aug cloud 6 & 2327 & 534 & 1793 & 2.44 & 14 \\
\hline 7 & 9 Aug cloud 2 & $* *$ & 690 & ** & $* *$ & 6 \\
\hline 8 & 9 Aug cloud 3 & 1681 & 486 & 1195 & 7.29 & 8 \\
\hline 9 & 9 Aug cloud 4 & 1676 & 742 & 934 & 2.62 & 4 \\
\hline Average & & 1890 & 557 & 1350 & 3.56 & Total $=60$ \\
\hline
\end{tabular}

* Average cloud width is obtained by averaging the cloud width throughout the cloud depth.

** Cloud-top altitude is not available for this cloud.

bandwidth and sample rate, which provided a spatial resolution of $10 \mathrm{~m}$ at the $50 \mathrm{~m} \mathrm{~s}^{-1}$ flight speed of the Twin Otter aircraft.

\section{Halo observations}

Nine missions were flown over the period 31 July10 August 2001, during which 44 individual cumulus clouds were sampled. Because of typically short cloud lifetimes, most of the sampled clouds were characterized by only a few (e.g., three) aircraft traverses. Subsequently we will present statistical data on the sampled clouds, in terms of frequency of halo occurrence and the spatial distribution. At 0047 UTC 8 August 2001, a particularly long-lived cumulus cloud (cloud 6 in Table 2 ) was encountered and sampled extensively. This cloud constitutes an ideal test case of a trade wind cumulus. For this reason, we devote considerable attention to measurements made on this cloud. We also focus on the ability to numerically simulate the development of this particular cloud because it provides an opportunity to study the development of the cloud halo and its radiative impact in some detail. As noted, for each traverse, the aircraft was at least $3 \mathrm{~km}$ away from the cloud lateral boundary at the beginning and end of the traverse. The aircraft made two complete cycles of penetrations from above cloud top to below cloud base; observation 1 consists of traverses 1 through 8 , and observation 2 corresponds to traverses 9 through 14 (Fig. 2). The total elapsed time of the 14 traverses through the cloud was 78 min.

The vertical profile of ambient conditions (Fig. 3) was acquired by the aircraft during vertical probing about $2.5 \mathrm{~h}$ before the cloud was sampled. The sounding profile features a tropical inversion layer between 1600$1900 \mathrm{~m}$, capping the trade wind boundary layer with stable, dry air. The sounding shows the atmosphere is conditionally unstable below $890 \mathrm{hPa}$, with an absolutely stable layer at $810-840 \mathrm{hPa}$. At its mature stage, the cloud base was at about $500 \mathrm{~m}$ and the top around $2200 \mathrm{~m}, 300 \mathrm{~m}$ above the top of the inversion layer, as shown in Fig. 4. The cloud was widest, $6-8 \mathrm{~km}$, at an altitude of about $1500 \mathrm{~m}$. The cloud region is operationally defined by a measured LWC exceeding $0.01 \mathrm{~g}$ $\mathrm{m}^{-3}$. The cloud width so defined might not necessarily correspond to the visible cloud width. The maximum and the horizontally averaged values of in-cloud LWC at each altitude, shown in Fig. 4b, exhibit a similar trend that increases with height until a point about $300 \mathrm{~m}$ below the cloud top, after which LWC falls rapidly to zero. This LWC trend is similar to that of Australian marine cumulus reported by Warner (1955). The cloud LWC and cloud width (Fig. 4) exhibited comparatively little change with time over the entire observation $(\sim 78$ min). This LWC persistency agrees with Warner's (1977) observations of small cumuli that the average turbulent velocity and LWC can last nearly unchanged for periods up to 20 min during the midstage of the cloud lifetime, although the life of the present cloud was relatively long compared with observations reported by Warner (1977). The mean and maximum LWC show similar vertical distribution patterns, also peaking around $2000 \mathrm{~m}$.

\section{a. Measured humidity profiles}

The measured humidity profile and LWC distribution for a particular traverse (traverse 12) are shown in Fig. 5 . We report the water vapor in terms of specific humidity with units of $\mathrm{g} \mathrm{kg}^{-1}$. An empirical expression similar to that used by Lu et al. (2002) is used to define the edge of the halo based on the $e$-folding decay of specific humidity $q_{\mathrm{ve}}(z)$, from the in-cloud average $\bar{q}_{\mathrm{vc}}(z)$, to the ambient value $\bar{q}_{\mathrm{venv}}(z)$ :

$$
q_{\mathrm{ve}}(z)=\bar{q}_{\mathrm{vc}}(z)-\left\{\left[\bar{q}_{\mathrm{vc}}(z)-\bar{q}_{\mathrm{venv}}(z)\right]\left(1-e^{-1}\right)\right\}
$$

The humidity far away from cloud lateral boundaries was not necessarily smooth; for example in Fig. 5, the smoothed data still show a wavy distribution with small amplitude. Because sounding profiles were not available for each cloud, we approximate $\bar{q}_{\text {venv }}(z)$ by averaging data points sufficiently far from the cloud. (Interestingly, 


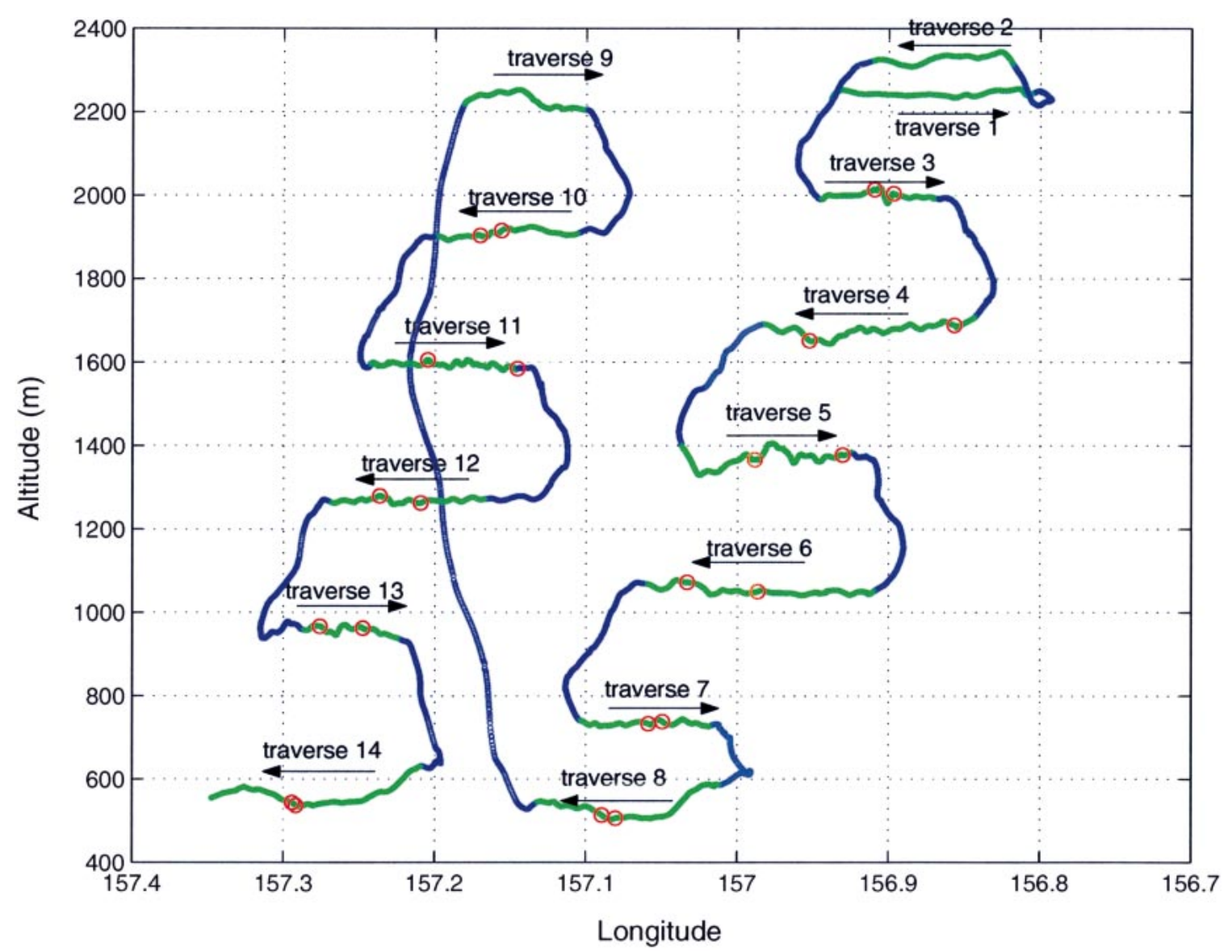

FIG. 2. Flight path for the cumulus cloud at 0047 UTC 8 Aug 2001. A total of 14 traverses (green) are shown. Observation 1 represents traverses 1 through 8; observation 2 represents traverses 9 through 14 . Red circles denote the cloud boundary.

the ambient values are not necessarily the same on both sides of the cloud.) From the smoothed data shown in Fig. 5, it can be seen that the measured humidity profile outside the cloud, beginning from the mark "c" to the two lower horizontal lines, can be approximated by an exponential decay. For some traverses, for example traverse 4 (Fig. 6), the aircraft did not fly far enough from the cloud to reach a constant ambient humidity. In this case, the humidities at the start and the end of the traverse are used to define the far-ambient humidities. Returning to Fig. 5, the humidity halo at the downshear side of the cloud is about four times broader than that at the upshear side.

The wind vector $\mathbf{u}$ is defined as positive in the positive $x$ direction for Cartesian coordinates $(x-z)$ in the eastwest and vertical directions. For example, an easterly wind is defined as negative. The vertical wind shear vector is defined as $d \mathbf{u} / d z$. The direction of the shear vector is positive if $d \mathbf{u} / d z>0$, and vice versa. The downshear and upshear directions are defined by the direction of the shear vector; in that sense, the shear vector always points in the downshear direction. The cloud morphology is tilted and stretched by the vertical shear, and the cloud is basically tilted to the downshear direction. Consider an easterly wind $(\mathbf{u}<0)$, the velocity of which decreases as $z$ increases; in this case, the shear vector is positive $(d \mathbf{u} / d z>0)$ and points in the positive $x$ direction. Then for a cloud, the downshear direction is in the positive $x$ direction, which is on the east side of the cloud. A westerly wind $(\mathbf{u}>0)$, the velocity of which increases with height, has the same direction of the shear vector as the previous case. Therefore, the downshear and upshear directions are the same in these two cases.

The vertical distribution of the humidity halo on both sides of the cloud was determined (Fig. 7). Perry and Hobbs (1996) found that the presence of a stable layer can limit the vertical distribution of the halo. In Fig. 7, in accord with this observation, we note that the cloud halo is distributed mainly below the inversion layer on both sides of the cloud. The vertical east-west wind profile shows a weak wind shear with the easterly wind increasing with height roughly below the inversion base where most of the halo is present; therefore, the downshear side is on the west side relative to the cloud. The vertical distribution of halo shows that halo width is largest at the lowest altitudes, decreasing with height below the inversion base, also in both of the downshear 


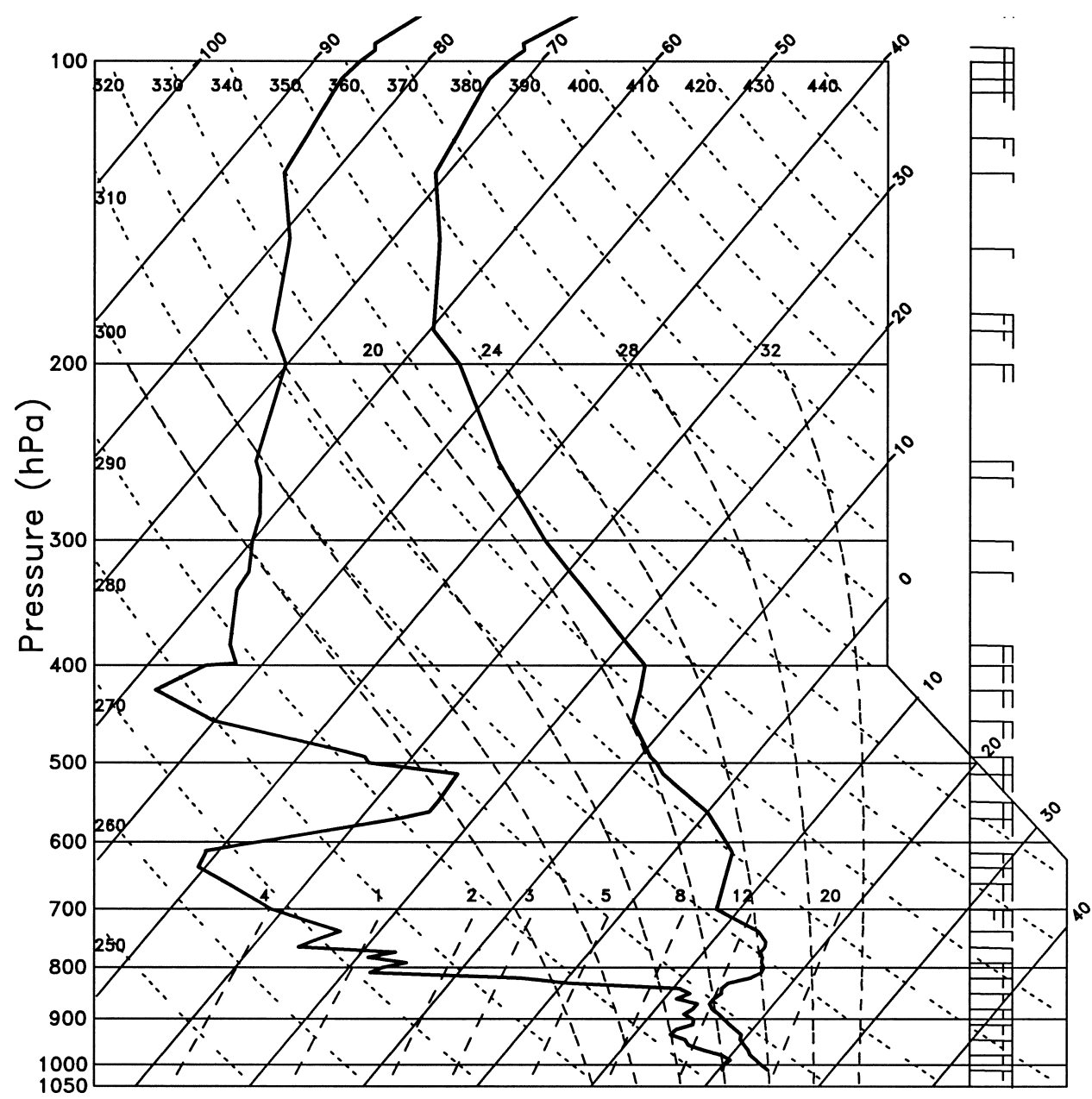

FIG. 3. Skew $T-\log p$ diagram of the ambient sounding profile on 8 Aug 2001 taken for the extensively studied cloud (see sections 3 and 4 ) at $0047 \mathrm{UTC}, 21.57^{\circ} \mathrm{N}, 156.82^{\circ} \mathrm{W}$. Temperature and dewpoint temperature profiles are represented by thick lines. The skewed abscissa is temperature $\left({ }^{\circ} \mathrm{C}\right)$, and the ordinate is pressure $(\mathrm{hPa})$. Dotted lines $(\mathrm{K})$ represent dry adiabats. Curved dashed lines $\left({ }^{\circ} \mathrm{C}\right)$ are pseudoadiabats. Straight dashed lines $\left(\mathrm{g} \mathrm{kg}^{-1}\right)$ are isopleths of the saturation water vapor mixing ratio. The north-south wind is not shown.

and upshear directions. This trend is similar to the observations of Perry and Hobbs (1996) that when the inversion layer lies in the middle of the cloud, the halo tends to be broader at the lower levels. The figure also shows the halo is wider in the downshear than the upshear direction. The peak of the halo width above the inversion base for observation 1 could be due to a hole in the cloud as shown in the simulation later. The halo becomes much broader at later times (e.g., observation 2 ) at the lower cloud levels in the downshear direction, but the halo at the upshear side stays relatively unchanged with time.

From the 44 individual clouds sampled over the twoweek period, we select nine clouds for which four or more traverses were made for statistical analysis (Table 2). Humidity halos were identified approximately 54\% of the time during the total of 60 traverses. All halos were less than two cloud radii in horizontal extent. In general, as indicated in Table 3, humidity halos are more frequent and broader at the downshear side $(55 \%$ and 0.67 cloud radii) than the upshear side $(44 \%$ and 0.41 cloud radii). The frequency of occurrence and width of the cloud halo on the upshear side observed in the present study are close to those of the cumulus clouds off the coasts of Oregon and Washington reported by Perry and Hobbs (1996); however, the frequency of occurrence and width at the downshear side in the present study are less than reported by Perry and Hobbs (1996). One possible explanation is that the clouds sampled in the present study consist of a higher fraction of young/ mature clouds.

The vertical distribution of these sampled halos is shown in Fig. 8. The data points are categorized into five altitude bins. The mean of the data for each altitude bin represents the halo width at that altitude range with the standard deviation as its error bar. The figure shows that the halo basically is broad at the lower levels of the cloud and narrow around cloud top. In this figure, 

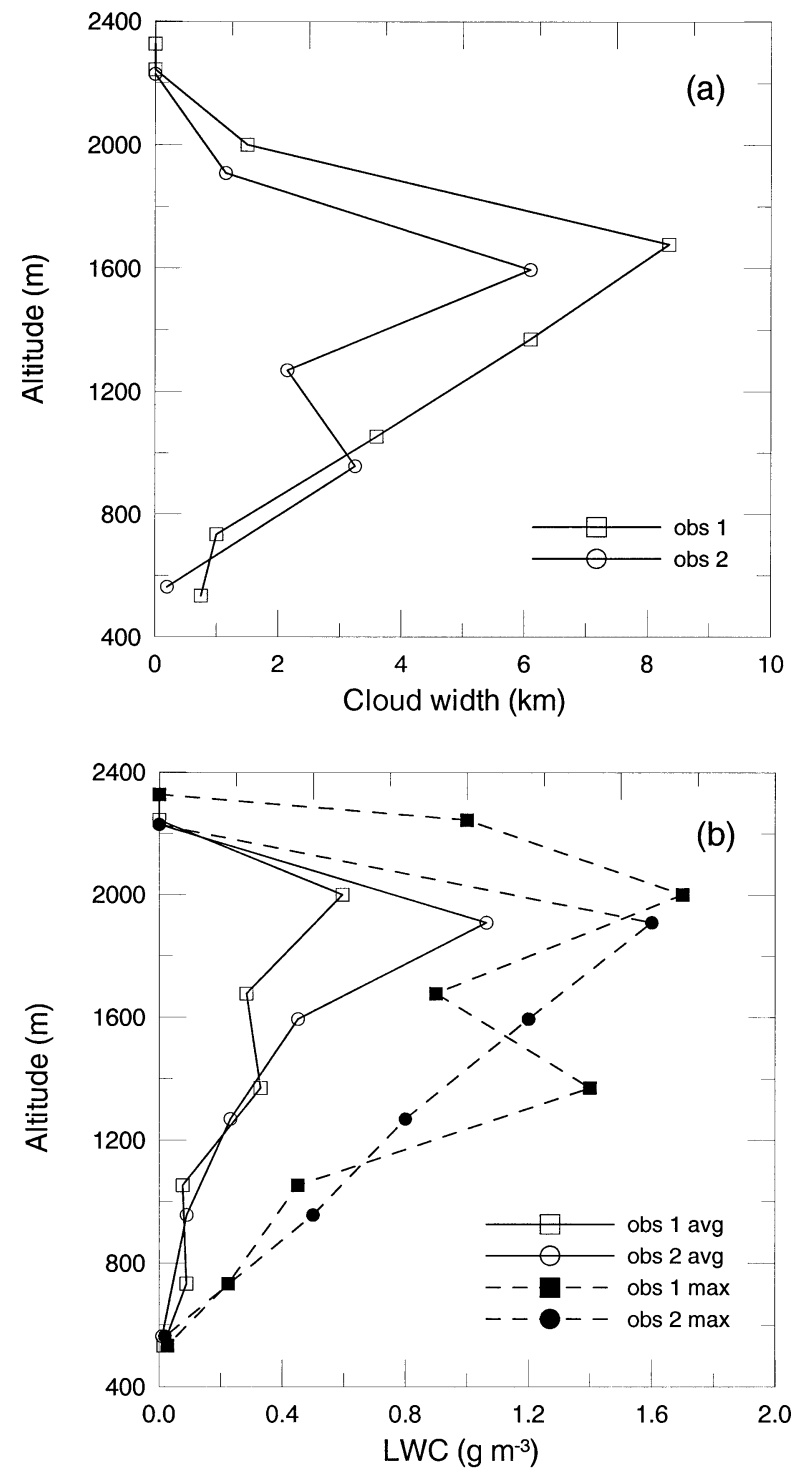

FIG. 4. Vertical profiles of (a) cloud width and (b) the horizontally averaged and maximum cloud LWC for each traverse for observations 1 (traverses 1-8) and 2 (traverses 9-14).

the large error bars for the downshear side suggests that the halo width is not a strong function of height. The sampled halo might correspond to different cloud ages because the halo width in the downshear direction increases with cloud age; however, the halo width decreases with height at the upshear direction, especially at lower levels. According to the study of Perry and Hobbs (1996), the vertical distribution of halos in the figure implies that the majority of clouds sampled in this study were at their young/mature stage.

\section{b. Aerosol and cloud droplet size distribution measurements}

Trade wind cumulus clouds are frequently situated in a transition region between the marine boundary layer and the free troposphere. Aerosol distributions in these two regions are typically quite different (Raes et al. 2000), and understanding the nature of new particle formation in each region remains an important issue. As noted in the introduction, new particle formation has been reported in the vicinity of clouds. Because of the elevated humidity, the cloud halo represents a potentially fertile region for new particle formation.

Typical profiles of the total particle concentration $\left(D_{p}\right.$ $>10 \mathrm{~nm})$ and particle size distribution $\left(0.10 \mu \mathrm{m}<D_{p}\right.$ $<3.5 \mu \mathrm{m}$ ) measured during the campaign are shown in Fig. 9. Generally, the total particle number concentration showed little variation within the marine boundary layer, and was about $150 \mathrm{~cm}^{-3}$. The total particle number concentration increased to about $300 \mathrm{~cm}^{-3}$ in the free troposphere, with a maximum near cloud top, at an altitude of $1900 \mathrm{~m}$ in the case shown. The number concentration of particles measured by the PCASP $(0.10$ to $3.5 \mu \mathrm{m}$ ) were anticorrelated with total particle number concentration; in this size range particle number concentration decreased from $60 \mathrm{~cm}^{-3}$ in the marine boundary layer to about $20 \mathrm{~cm}^{-3}$ in the free troposphere. This change is likely due to aerosol processing by clouds within the marine boundary layer, which produces particles with diameters that fall into the PCASP measurement range.

Figure 9 shows a typical example of the dry aerosol size distributions measured in the vicinity of clouds at different altitudes. Based on the characteristics and measurement altitudes, the size distributions are grouped into three categories: free troposphere, transition region, and marine boundary layer. The size distributions are shown as $d N / d \log D_{p}\left(\mathrm{~cm}^{-3}\right)$. In the free troposphere, the aerosol generally has the highest number concentration, with the majority of the particles smaller than $0.1 \mu \mathrm{m}$. The size distribution is unimodal with a peak concentration of about $300 \mathrm{~cm}^{-3}$ at about $65 \mathrm{~nm}$ (A and G; Fig. 9c). In the marine boundary layer (Fig. 9e), particles displayed typical bimodal distributions that result from aerosol processing through nonprecipitating cloud cycles. The mode at the smaller diameter $(\sim 45$ $\mathrm{nm}$ ), which is too small to be activated to form cloud droplets, is often referred to as the interstitial mode. The mode near $200 \mathrm{~nm}$ results from evaporated cloud droplets; these particles are larger than their precloud sizes, mainly as a result of uptake of soluble trace gases and subsequent conversion to nonvolatile compounds. Within the marine boundary layer, the aerosol size distributions at different altitudes (D, E, F, J, and K) are similar to each other. The peak concentrations of the two modes are about 150 and $220 \mathrm{~cm}^{-3}$. The local minimum between the two modes is at $75 \pm 10 \mathrm{~nm}$, which reflects the supersaturation in the clouds (Hoppel et al. 1996). Assuming the aerosol to be composed mainly of $\mathrm{NH}_{4} \mathrm{HSO}_{4}$, the supersaturation of the marine boundary layer clouds is estimated as $0.075 \% \pm 0.02 \%$.

The aerosol distributions at locations B, H, C, and I, which are measured near the inversion layer (Fig. 9d), 


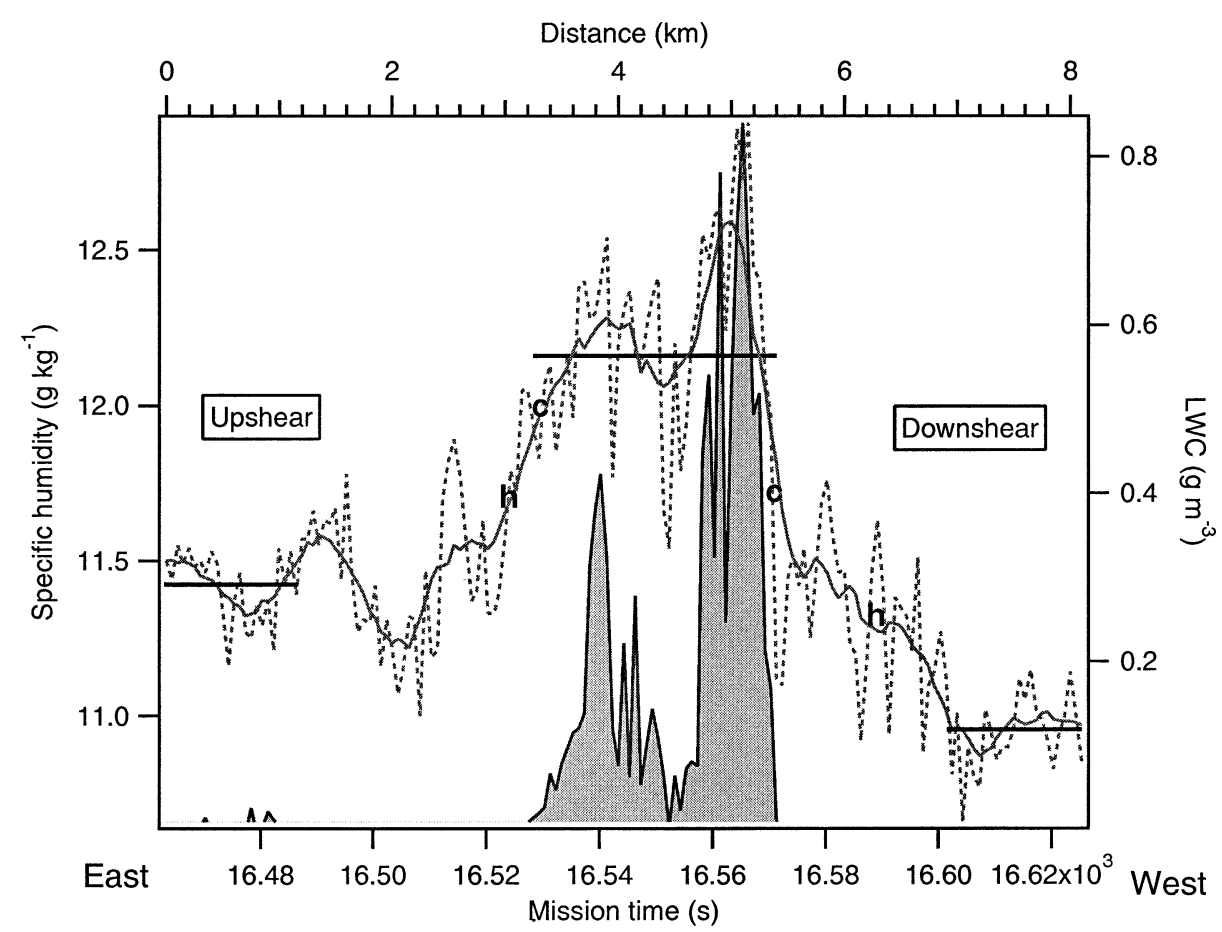

FIG. 5. Specific humidity $\left(\mathrm{g} \mathrm{kg}^{-1}\right)$ distribution on aircraft traverse 12 . The dotted line is the actual data, and the solid line through it are the smoothed data (11-point moving average of the dotted line). The shaded area is the cloud liquid water content $\left(\mathrm{g} \mathrm{m}^{-3}\right)$. The cloud boundary is defined by a liquid water content of $0.01 \mathrm{~g} \mathrm{~m}^{-3}$ and is displayed as "c," and the edge of the halo is denoted by " $\mathrm{h}$ " in the humidity distribution. The horizontal line in the cloud area is the in-cloud specific humidity $\bar{q}_{\mathrm{vc}}(z)$, while the two lines outside the cloud are the environmental specific humidity $\bar{q}_{\text {venv }}(z)$. The distance from the start of this traverse is given on the top axis.

displayed a transition from free tropospheric to marine boundary layer aerosol. As the average measurement altitude decreases into the marine boundary layer, the mode resulting from evaporated cloud droplets emerges.

Particles resulting from recent nucleation events were observed at three altitudes $(1500,1180$, and $900 \mathrm{~m}$, Fig. 9a) on the downshear side of the cloud (cloud 6 in Table 2 ). The newly formed particles were evidenced by the difference between the particle concentrations reported by the three CNCs, which have different detection limits of 3, 6, and $10 \mathrm{~nm}$, respectively (Figs. 9f-g). In all three cases, the newly formed particles were observed in the region with high relative humidity, a condition that favors homogeneous nucleation.

\section{Numerical simulation}

Lu et al. (2002) evaluated the ability to numerically simulate cloud and halo development for several cases that have been reported in the literature. The numerical simulations focused on the development of humidity regions around the clouds (these regions had not necessarily been probed in the reported aircraft studies). In this section, we numerically simulate the large, persistent cloud discussed in detail in section 3 , for which we employ the three-dimensional, nonhydrostatic version of RAMS (Pielke et al. 1992; Walko et al. 1995).

Jiang and Cotton (2000) conducted a large eddy simulation of trade-wind cumulus convection in Barbados using RAMS. The simulation was initialized by imposing a random white noise in temperature at the lowest levels of the model. With initial random temperature fluctuations, many small cumuli tend to evolve in the domain (e.g., Stevens et al. 2001). An alternate initialization procedure, better suited to generating a single cloud, is to apply a thermal bubble method. The thermal perturbation is assumed to be a Gaussian function, similar to that used by Steiner (1973), $\theta^{\prime}=\alpha \exp \{-[(x$ $\left.\left.\left.-x_{c}\right) / 0.5 \lambda_{m}\right]^{2}\right\} \sin ^{2}(\pi z / h)$, where $\alpha$ is the maximum amplitude of the perturbation, $x_{c}$ is the center of the model domain, $\lambda_{m}$ is a characteristic horizontal length scale of the thermal fluctuation (McNider and Kopp 1990), and $h$ is the effective perturbation depth. The size of the initial pulse greatly influences the numerical development of the cloud (e.g., Murray 1971). Different perturbations were tested to find that for which the simulated cloud resembled that observed. An initial thermal perturbation of $\alpha=0.1 \mathrm{~K}$ with $\lambda_{m}=632 \mathrm{~m}$ applied in the central domain of $1 \mathrm{~km} \times 1 \mathrm{~km}$ below $h=500 \mathrm{~m}$ produced a simulated cloud closest to that observed. 


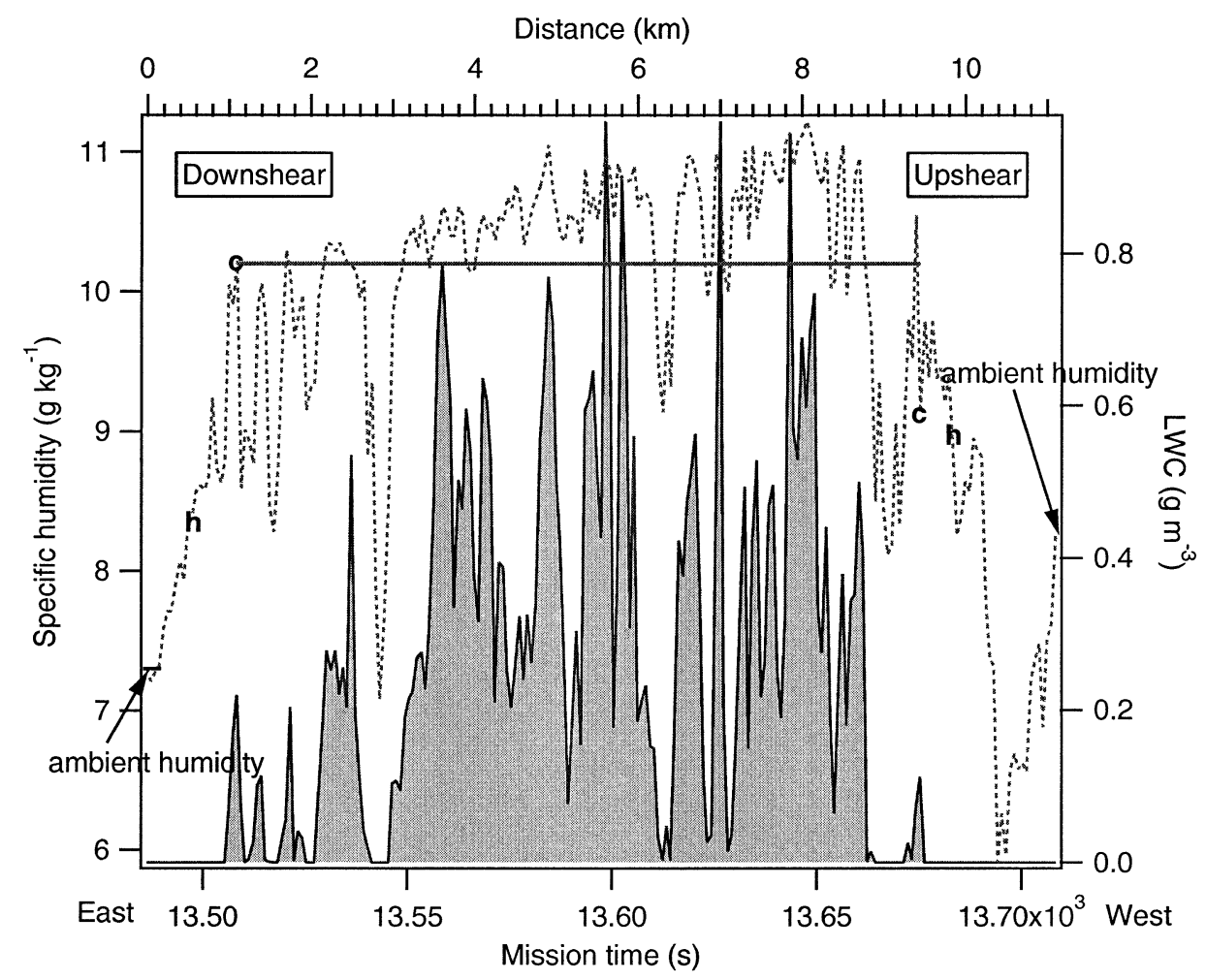

FIG. 6. Same as Fig. 5 but for traverse 4. The ambient specific humidity is defined as that at the start and end of the traverse.

(Although cases were tried with $\lambda_{m}=4 \mathrm{~km}$, close to the observed averaged cloud width, this perturbation did not produce a cloud similar to that observed.) Our experience shows that a humidity perturbation saturating

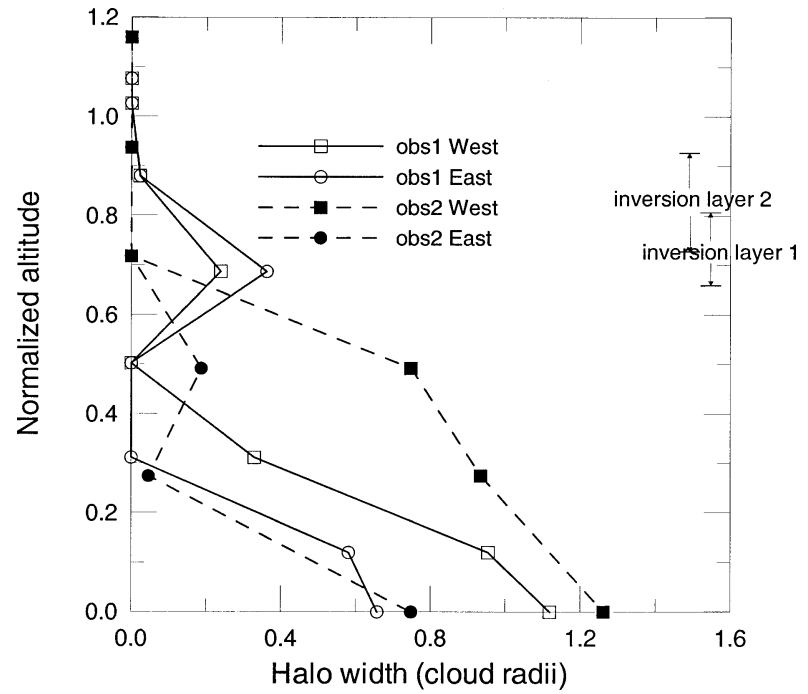

FIG. 7. Vertical profile of cloud halo width at the west and east sides of the cloud vs the altitude normalized with the cloud depth for observations 1 and 2 . The normalized altitudes of 0 and 1 refer to cloud base and cloud top, respectively. Below the inversion base, the west side relative to the cloud is the downshear direction. the lower levels (e.g., below $214 \mathrm{~m}$ ) of the model, confined in the central region, is required. We have arbitrarily set the $v$ component of wind to be zero, so that the cloud movement can be followed easily.

The simulation domain has a horizontal resolution of $100 \mathrm{~m}$, equivalent to a 2-s measurement resolution (at 50 $\mathrm{m} \mathrm{s}^{-1}$ flight speed), and vertical resolution of $40 \mathrm{~m}$ at the lowest altitude with a vertical stretching ratio of 1.1. The simulation domain is thus $6 \mathrm{~km} \times 6 \mathrm{~km} \times 11 \mathrm{~km}$, the horizontal domain size being large enough to cover the cloud and the associated cloud halo. The sea surface temperature (SST) was prescribed using the National Centers for Environmental Prediction (NCEP) Reynolds average SST of $300 \mathrm{~K}$ (see Web site http://podaac.jpl.nasa.gov/ reynolds/reynolds_browse.html) in the vicinity of Hawaii in August 2001. The lateral boundary condition is periodic, and the upper and lower boundaries are rigid lids. The averaged cloud droplet size distribution (Fig. 10) observed during traverse 7 by the FSSP-100, was integrated over the droplet spectrum to give a cloud droplet number concentration $\left(N_{t}\right)$ of $76 \mathrm{~cm}^{-3}$. By fitting the data with a modified gamma distribution used in RAMS (Walko et al. 1995),

$$
n(D)=\frac{N_{t}}{\Gamma(\nu)}\left(\frac{D}{D_{n}}\right)^{\nu-1} \frac{1}{D_{n}} \exp \left(-\frac{D}{D_{n}}\right)
$$

with this cloud droplet number concentration value, we 
TABle 3. Cloud halo statistics for the current study as compared with Perry and Hobbs (1996).

\begin{tabular}{|c|c|c|c|c|c|c|}
\hline \multirow[b]{2}{*}{$\begin{array}{l}\text { Wind } \\
\text { direction }\end{array}$} & \multicolumn{3}{|c|}{ This study: Hawaii trade wind cumulus } & \multicolumn{3}{|c|}{$\begin{array}{c}\text { Perry and Hobbs (1996): Cumulus clouds off the coast of } \\
\text { Oregon and Washington }\end{array}$} \\
\hline & $\begin{array}{l}\text { Sample } \\
\text { size }\end{array}$ & $\begin{array}{l}\text { Halo } \\
\text { frequency }\end{array}$ & $\begin{array}{c}\text { Averaged } \\
\text { halo width } \\
\text { (cloud radii) }\end{array}$ & $\begin{array}{l}\text { Sample } \\
\text { size }\end{array}$ & $\begin{array}{l}\text { Halo } \\
\text { frequency }\end{array}$ & $\begin{array}{c}\text { Averaged } \\
\text { halo width } \\
\text { (cloud radii) }\end{array}$ \\
\hline Downshear & 38 & $55 \%$ & 0.67 & 56 & $75 \%$ & 1.3 \\
\hline Upshear & 39 & $44 \%$ & 0.41 & 57 & $35 \%-40 \%$ & 0.3 \\
\hline
\end{tabular}
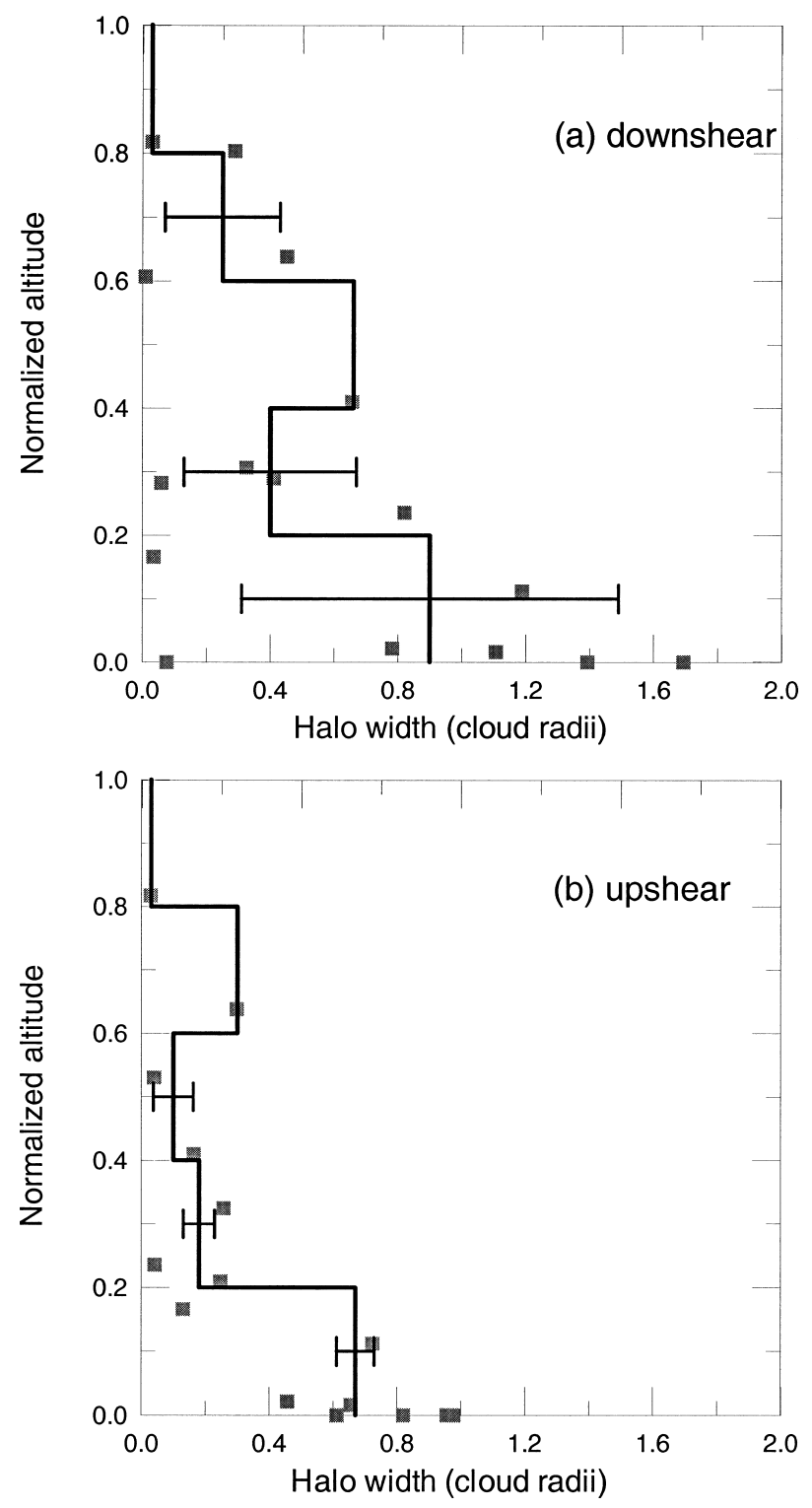

FIG. 8. Vertical profile of the halo width for the sampled clouds shown in Table 2 in the (a) downshear and (b) upshear directions of the cloud. The data points are categorized into five altitude bins. The thick solid line is the averaged halo width of each altitude bin. Error bars indicate the standard deviations of the data points in each altitude bin. The square symbols indicate the observational data points. obtain the gamma distribution shape parameter $\nu=7.8$ and the characteristic diameter $D_{n}=1.8 \mu \mathrm{m}$. The observed cloud droplet size distribution shown in Fig. 10 is well represented by a gamma distribution.

The simulated cloud at 16 min (Fig. 11) most closely resembles that during the period of observation. The simulated cloud base and top are around 500 and 2000 $\mathrm{m}$, respectively, which are close to the observation (300 and $2200 \mathrm{~m}$ ). The cloud top is a few hundred meters above the inversion, as also seen in observations by Raga et al. (1990). The vertical profile of the simulated maximum LWC at 16 min, shown in Fig. 12, exhibits reasonable agreement with the observed vertical profile and values of the maximum LWC. The simulated maximum LWC is only slightly smaller than the observation. Also, the simulated vertical profile of the maximum specific humidity at $16 \mathrm{~min}$ matches that sampled. Since the simulated cloud is smaller than the observation, the simulated halos are expressed in units of cloud radii so that the factor of absolute cloud width can be eliminated. The vertical profile of the simulated cloud halo (Fig. 13) agrees well with the observation (Fig. 7). For example, the simulated halo is similar to the observation 2 (1) below (above) 0.6 cloud depth. The broadest halo is predicted at the cloud base with the width of 0.6 cloud radii at the upshear side and 1.5 cloud radii at the downshear side, as compared to the observations of 0.7 cloud radii and 1.3 cloud radii, respectively. The peak value of the halo width at a cloud depth of 0.7 in Fig. 7 resulted from the hole in the cloud (Fig. 11). In general, the simulated halo is broader at the downshear side of the cloud than the upshear side throughout the simulated cloud life. However, in this simulation, the cloud only lasts for $24 \mathrm{~min}$, considerably shorter than the observation $(78 \mathrm{~min})$.

In order to demonstrate a clear relationship between the halo and the shear vector, we conduct a simulation by increasing the wind shear. In the presence of wind shear, the cloud is tilted and stretched in the downshear direction, and the cloud is basically moving with the dominant ambient easterlies. This simulation shows the cloud is growing on the upshear side and dissipating on the downshear side, as reported in the numerical simulation (e.g., Vaillancourt et al. 1997) and observation (e.g., Telford and Wagner 1980). Results in Fig. 14a show an asymmetric distribution of halo relative to the cloud, and the halo is encompassed by an asymmetric 

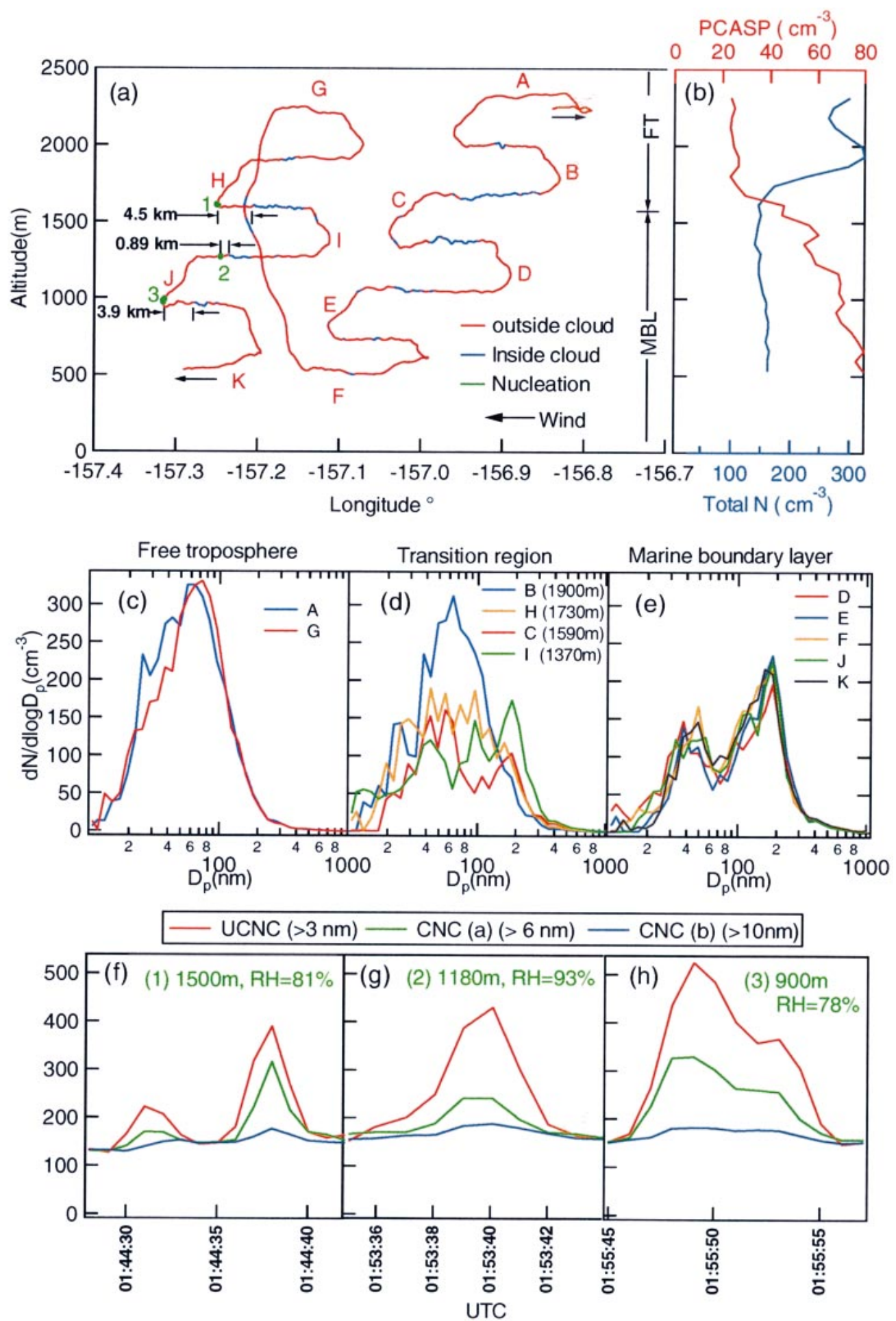

FIG. 9. (a) Flight track during sampling of a convective cumulus cloud from 0050 to 0204 UTC 6 Aug 2001, with different altitudes labelled A-K; (b) vertical profile of total particle concentration and particle concentration in the size range 0.1 to $3.5 \mu \mathrm{m}$ diameter; (c)-(e) dry aerosol size distributions in free troposphere, transition region, and marine boundary layer; (f)-(g) particle concentrations measured by three CNCs when newly formed particles were detected. 


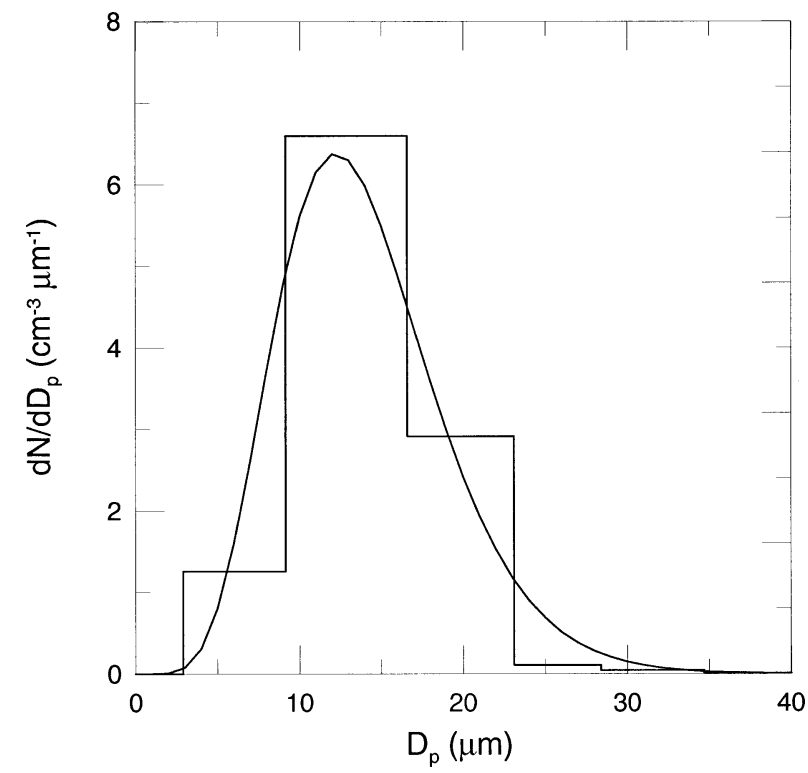

FIG. 10. Averaged cloud droplet size distribution for traverse 7, together with continuous fitted gamma distribution [Eq. (2)] used for simulation.

clear-air turbulence adjacent to the cloud. Dissipation of the cloud formed previously can produce the halo. However, the halo forming on the upshear side of the cloud in Fig. 14a is in the direction of cloud propagation (also the halo on the downshear side of the cloud in Fig. 11), and cannot be due to the remains of the cloud formed previously. The vertical wind velocity in this area shows the updraft velocity outside the cloud boundary at the upshear side and a large fluctuation with updraft and downdraft at the downshear side. Therefore, the high correlation of clear-air turbulence area with the halo distribution suggests that lateral turbulent mixing of the humid cloudy air with dry ambient air can either evaporate the cloud droplets or detrain the high humidity outside the cloud boundary and produce the halo. This clear-air turbulent mixing area is broader at the dissipating downshear side than at the growing upshear side. The above mechanism and the cloud-environment relative motion result in this asymmetric halo distribution. This strong correlation of the asymmetric halo distribution with the turbulent mixing area also emerged in the previous simulation (Fig. 11) and observations of Malkus (1949) and Ackerman (1958). When the cloud starts to dissipate, the dissipated cloud gradually leaves a broad area of humidity halo and turbulence (Fig. 14b). At this time, the halo is not only limited to the lower levels but distributed vertically.

In summary, while the simulated cloud width and lifetime are smaller than those of the observed cloud, the vertical profiles of LWC and water vapor, the locations of cloud top and base, and the magnitude and the vertical profile of the cloud halo width (in terms of cloud radii) in different wind shear regimes agree well with observation. By conducting a numerical experiment with increased vertical wind shear, we find the halo distribution is highly correlated with the clear-air turbulence, temporally and spatially, as also seen in past observations. This suggests that turbulent mixing at the

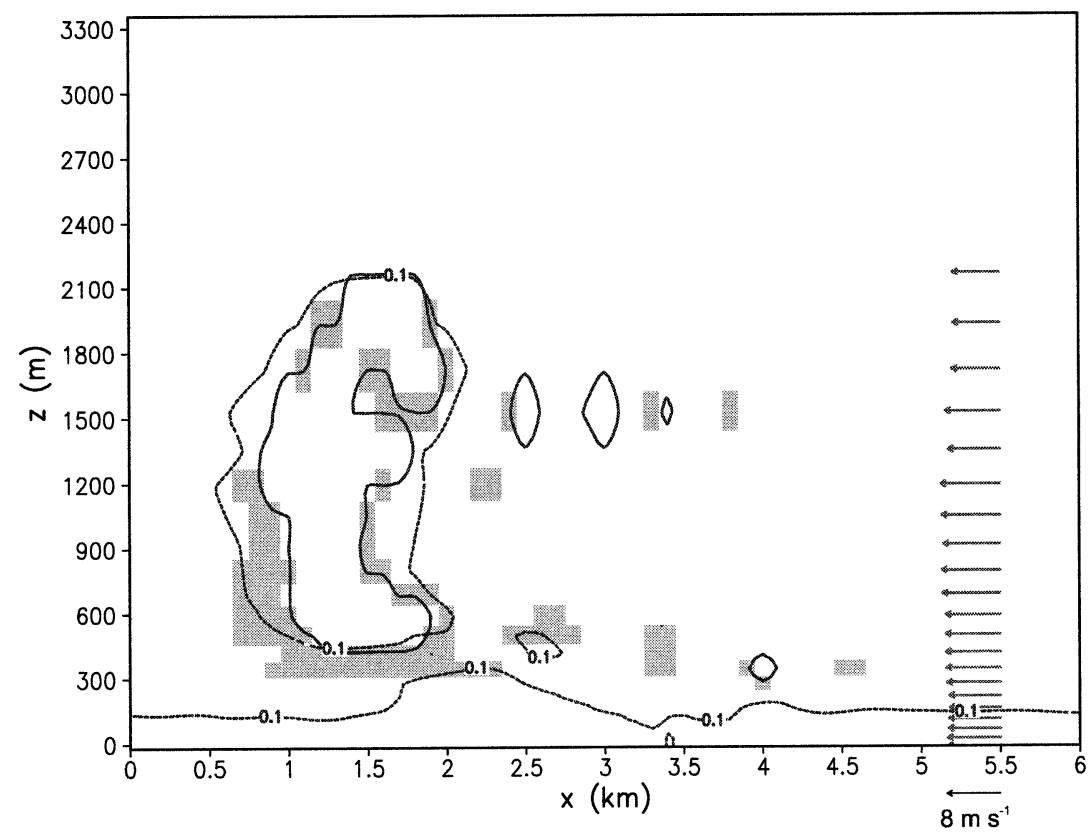

FIG. 11. Simulated cloud (LWC contour line of $0.01 \mathrm{~g} \mathrm{~m}^{-3}$ ) and cloud halo (shaded regions) at $t=16 \mathrm{~min}$. Below the inversion base, the west side of the cloud is the downshear side. The dotted line is the isopleth of turbulent kinetic energy of $0.1 \mathrm{~m}^{2} \mathrm{~s}^{-2}$. The vertical profile of horizontal wind speed is shown as horizontal arrows. 

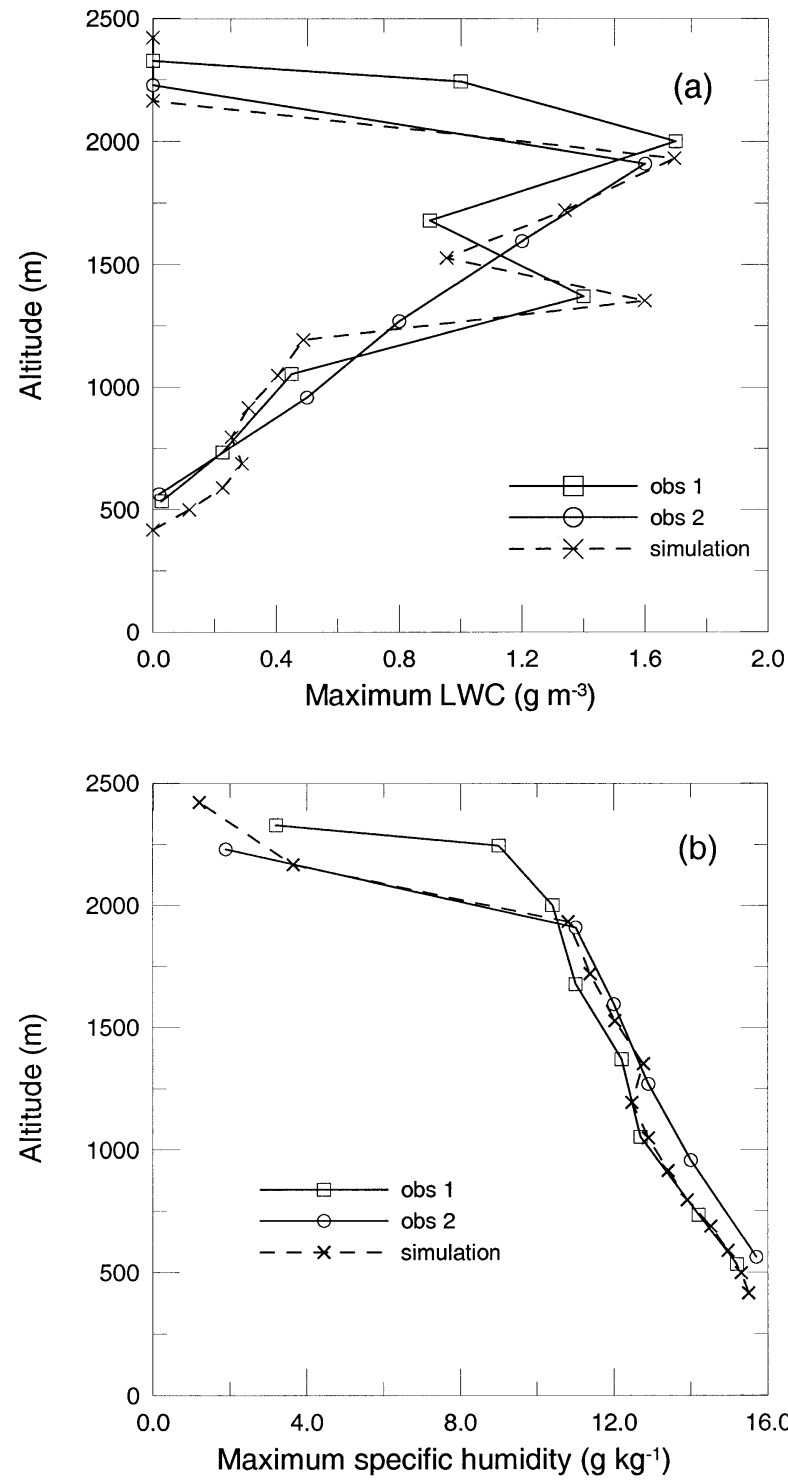

FIG. 12. Vertical profiles of the maximum (a) LWC and (b) specific humidity from RAMS simulation at $t=16 \mathrm{~min}$, observation 1 and observation 2 .

cloud boundary can evaporate cloud droplets or detrain high humidity to the adjacent clear-air region, in addition to the remains of the cloud formed previously, producing the halo.

\section{Simulated radiative effect of cloud and halo}

The simulated cloud and other atmospheric properties are used as input for a radiation calculation. The 3D radiative transfer model utilized in this study is the spherical harmonic discrete ordinate method (SHDOM; Evans 1993, 1998). For the SW broadband $(0.2-4 \mu \mathrm{m})$ calculation, the correlated $k$ distribution ( $\mathrm{Fu}$ and Liou 1992 ) is assumed for the gaseous absorption by methane, ozone, nitrous oxide, carbon dioxide, and water

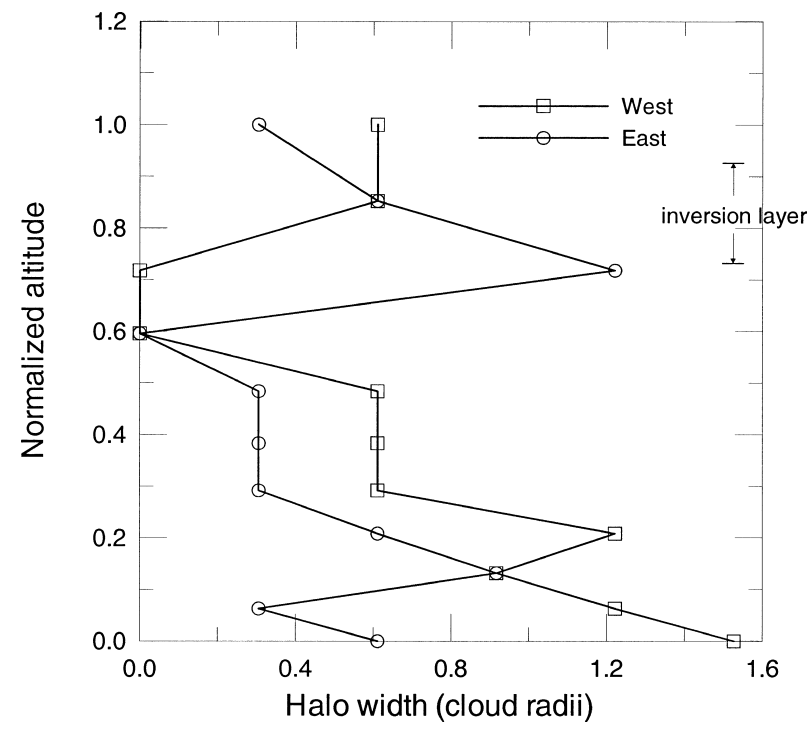

FIG. 13. Vertical profile of the simulated cloud halo as shown in Fig. 11 at the west side and east side of the cloud at $t=16 \mathrm{~min}$. Wind is from the east. Below the inversion base, the west side relative to the cloud is the downshear direction.

vapor. There are a total of $54 k$ values over the six solar bands. Cloud droplet optical properties are calculated based on Mie theory. The model has been modified to allow a 3D water vapor distribution for the purpose of calculating the halo radiative effect.

The 2D simulated cloud and its associated halo from RAMS serve as input into the 3D SHDOM due to the extensive computation time involved for the $3 \mathrm{D}$ cloud geometry. The radiative calculation by SHDOM is carried out every two minutes. The solar zenith and azimuthal angles at the time of measurement are $33.38^{\circ}$ $(\cos \theta=0.835)$ and $177.2^{\circ}$, respectively. In the calculation, there are 8 zenith angles in both hemispheres and 16 azimuthal angles used to calculate radiation flux. One important issue associated with the cloud halo is the amount of solar energy absorbed by it. Based on the radiative energy balance, the atmospheric absorption between two altitudes $z_{a}$ and $z_{b}\left(z_{b}<z_{a}\right)$ for a vertical column located at $x$ of a 2D $(x-z)$ medium can be calculated by (see the appendix of Marshak et al. 1998)

$$
\int_{z_{b}}^{z_{a}}-\frac{\partial F_{z}}{\partial z} d z+\int_{z_{b}}^{z_{a}}-\frac{\partial F_{x}}{\partial x} d z
$$

where $F_{z}$ is the net downward flux $\left(\mathrm{W} \mathrm{m}^{-2}\right)$ and $F_{x}$ is the net horizontal flux in the $x$ direction. If the domainaveraged horizontal photon transport is zero, that is,

$$
\frac{1}{L} \int_{0}^{L} \int_{z_{b}}^{z_{a}}-\frac{\partial F_{x}}{\partial z} d z d x=0,
$$

where $L$ is the length of the horizontal domain $(x)$, the atmospheric absorption can be calculated by only the first term of Eq. (3). Because of the cyclic boundary condition used for the SHDOM calculation, we can ap- 
ply Eq. (4) so that the domain-averaged (over the $x$ axis) atmospheric absorption $(A)$ is simply

$$
\frac{1}{L} \int_{0}^{L}\left[F_{z}\left(z_{a}\right)-F_{z}\left(z_{b}\right)\right] d x \cong \sum_{i=1}^{N_{x}}\left[F_{z}\left(z_{a}\right)-F_{z}\left(z_{b}\right)\right]_{i},
$$

where $N_{x}$ is the number of grid cells in the $x$ direction. Figure 15 shows the atmospheric column absorption (between the surface and $3.4 \mathrm{~km}$ ) both in the presence and absence of the halo. The absence of the halo scenario is established numerically by replacing the absolute humidity of the halo region (shaded boxes as shown in Fig. 11) with that of the far ambient; therefore, the difference of the two scenarios represents the maximum halo radiative effect. The largest value of the haloenhanced SW column absorption $(\Delta A$; dotted line in Fig. 15) is $2.49 \mathrm{~W} \mathrm{~m}^{-2}(2.3 \%$ of the column absorption without the halo, $\left.106.29 \mathrm{~W} \mathrm{~m}^{-2}\right)$, which appears at 18 min simulation time when the lower portion of the cloud dissipates, leaving a significant amount of high humidity. It is noted that $\Delta A$ strongly depends on the cloud age, the magnitude being small when the cloud is forming but becoming larger at the mature and dissipation stages. The enhanced atmospheric absorption due to the halo averaged over the mature and dissipation stages of the cloud is $1.32 \mathrm{~W} \mathrm{~m}^{-2}$, approximately $1.3 \%$ of the column absorption in the absence of the halo (103.28 $\mathrm{W} \mathrm{m}^{-2}$ ). We are also interested in estimating the amount of the increased SW absorption of the cloud over its lifetime. Although information on the measured cloud before or after the observations is not available, we can utilize the model results to perform this calculation. The value of $\Delta A$ averaged over the simulated cloud lifetime of $24 \mathrm{~min}$ is $0.63 \mathrm{~W} \mathrm{~m}^{-2}$, corresponding to a $0.6 \%$ increase of the column absorption over that without the halo $\left(103.78 \mathrm{~W} \mathrm{~m}^{-2}\right)$.

The spatial pattern of the radiative effect of the cloud halo at simulation time $16 \mathrm{~min}$ is shown in Fig. 16. This figure represents the difference between radiative heating rates in the presence and absence of the cloud halo. Because the radiative heating rate is proportional to the absorbed power per unit volume, the positive values in the figure indicate that there is increased absorption due to the halo. Figure 16 shows maxima near the cloud top at both sides, with maximum value of $0.32 \mathrm{~K} \mathrm{~h}^{-1}$ at $2100 \mathrm{~m}$. Other simulation results (not shown) also show that the largest local halo radiative effect is located near the cloud top, and this local effect is largest for the mature cloud. Both simulated and observed clouds are relatively shallow, without an anvil or horizontal outflow region.

Conant et al. (1998) and Vogelmann et al. (1998) find little discrepancy between predictions of radiative transfer models of water vapor absorption and observations for the case of clear skies. Arking (1999), however, reports some discrepancy when clouds are present. Some enhancement of atmospheric absorption will exist due to cloud inhomogeneity (Marshak et al. 1998). Be- cause of the covariance of cloud fields and water vapor fields in trade cumulus systems and the potential enhancement in atmospheric absorption this geometry produces, a question relevant in the present simulation is the extent to which cloud halos contribute to discrepancies between observed and predicted atmospheric absorption based on the assumption of horizontally homogeneous water vapor fields.

In summary, the radiative effect of the halo depends on the stage of the cloud development and the location with respect to the cloud. The halo radiative effect is largest near the cloud top during the cloud mature and dissipation stages. The enhanced SW column absorption (surface to $3.4 \mathrm{~km}$ ) averaged over this period for the simulated cloud is $1.32 \mathrm{~W} \mathrm{~m}^{-2}$, contributing $1.3 \%$ change to the column absorption in the absence of the halo. However, the enhanced absorption is only $0.63 \mathrm{~W}$ $\mathrm{m}^{-2}(0.6 \%)$ averaged over the simulated cloud lifetime. This represents a small fraction of the $6 \%$ discrepancy between models and observations reported by Arking (1999) and others and commonly referred to as "anomalous cloud absorption."

\section{Conclusions}

An aircraft campaign sampling trade wind cumulus clouds, Cloud Halo, was conducted in the vicinity of Oahu, Hawaii, in July-August 2001, the main purpose of which was to study humidity distributions around the clouds. One especially persistent cloud was extensively sampled and numerically simulated using the RAMS model. The simulated cloud, though narrower than the actual, resembled the observations with respect to locations of cloud top and base, vertical distribution and magnitude of maximum/mean LWC, maximum specific humidity, and halo vertical profile and width at the mature cloud stage. The halo broadens with time at the lower levels at the downshear side of the cloud. Both observations and simulations suggest that an inversion layer limits the presence of cloud halos to below the layer.

Among 60 traverses through clouds, halos were identified around half of the time, all of which had spatial extent less than two cloud radii. The frequency of occurrence and width of the halos in the downshear and upshear directions are 55\% and 0.67 cloud radii and $44 \%$ and 0.41 cloud radii, respectively. In the young/ mature stage of cloud development, halos tend to be broad at the lower levels of the clouds and narrow around the cloud top, on both sides of the cloud. The halos are also broader in the downshear direction than in the upshear direction.

Numerical simulation shows the asymmetric halo distribution relative to the cloud in the presence of vertical wind shear is associated with the asymmetric clear-air turbulence area, in agreement with past observations in Malkus (1949) and Ackerman (1958). Therefore, the simulation results suggest that turbulent mixing of the 

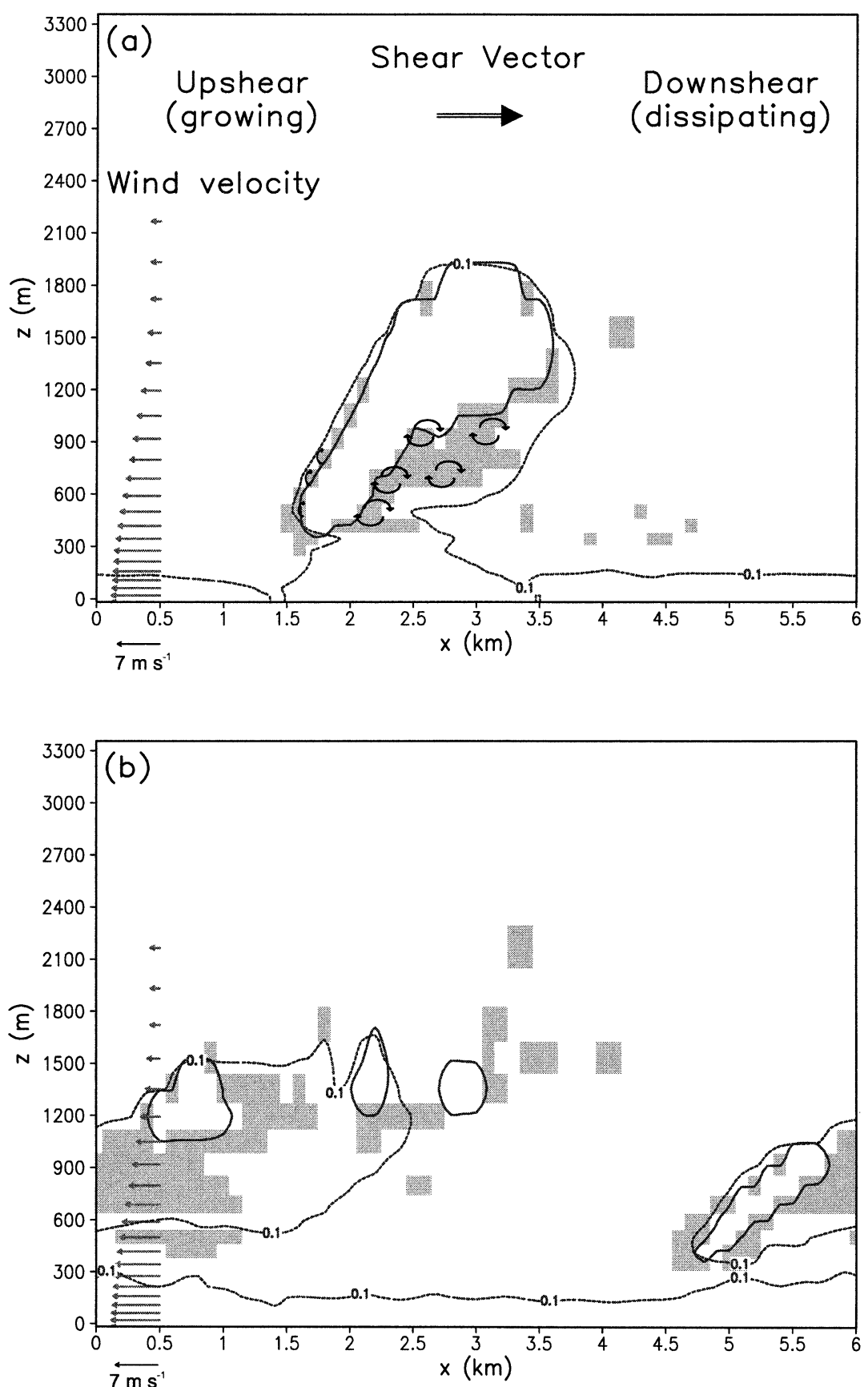

FIG. 14. Halo (shaded regions) simulation by imposing a stronger wind shear into the simulation as shown in Fig. 11 for (a) mature stage and (b) dissipation stage. The turbulent mixing area is encompassed by the isopleth (dotted) of turbulent kinetic energy of $0.1 \mathrm{~m}^{2}$ $\mathrm{s}^{-2}$. The vertical profile of horizontal wind speed is shown as horizontal arrows. The LWC contour line (solid) of $0.01 \mathrm{~g} \mathrm{~m}^{-3}$ represents the cloud.

humid cloudy air with the dry adjacent clear air can either evaporate cloud droplets or detrain the high humidity from the cloud boundary, adding it to the halo resulting from the remains of the cloud formed previously. Because of growth on the upshear side and dissipation on the downshear side, the halo is broader on the downshear than the upshear side of the cloud. Sim- ulation also shows that the halo distribution broadens with cloud age.

Observations and simulation of the cloud halos in this study generally agree with observations of Perry and Hobbs (1996) and numerical simulations of Lu et al. (2002). The trade wind cumulus clouds sampled in this study were shallow clouds without anvils or cloud out- 


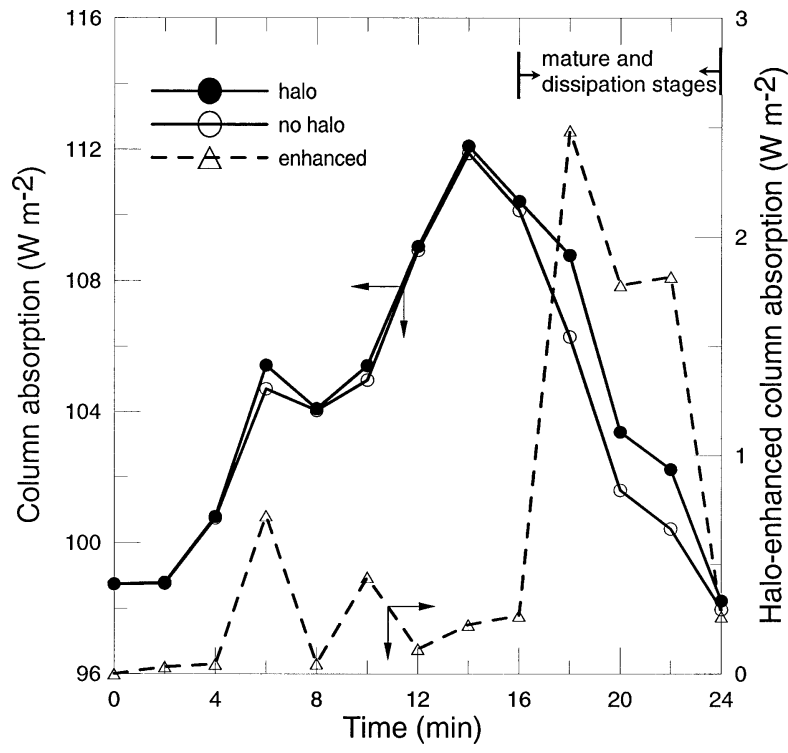

FIG. 15. Domain-averaged (over the $x$ axis) SW atmospheric column (surface to $3.4 \mathrm{~km}$ ) absorption $(A)$ as a function of simulation time in the presence and absence of humidity halo. The dotted line is the halo-enhanced atmospheric absorption $(\Delta A)$. flows. We can expect that more convective clouds, such as thunderstorms or clouds in the ITCZ, with cloud outflow regions near cloud tops, will exhibit broader halos.

Regions in the vicinity of clouds are favorable for new particle formation. Aerosols measured in the vicinity of the trade wind cumulus clouds reflected three regimes: free troposphere, transition zone, and marine boundary layer. In the free troposphere, the aerosol size distribution was found to be unimodal with a peak size at about $65 \mathrm{~nm}$, while being bimodal in the marine boundary layer with peaks at about 45 and $185 \mathrm{~nm}$. These observations are consistent with prior measurements reported in the literature. Particles resulting from recent nucleation events, when observed, occurred on the downshear side of the cloud, coincident with the region of largest halo.

Radiative absorption of the simulated halo has been estimated using the radiative transfer model SHDOM. Results show that the halo radiative effect is largest at the cloud mature and dissipating stages. A peak column absorption (surface to $3.4 \mathrm{~km}$ ) due to the halo of 2.49 $\mathrm{W} \mathrm{m}^{-2}(2.3 \%)$ is noted early in the cloud dissipation stage. The temporally and spatially averaged SW column absorption during this period for the simulated cloud is $1.32 \mathrm{~W} \mathrm{~m}^{-2}$, a $1.3 \%$ increase of the column

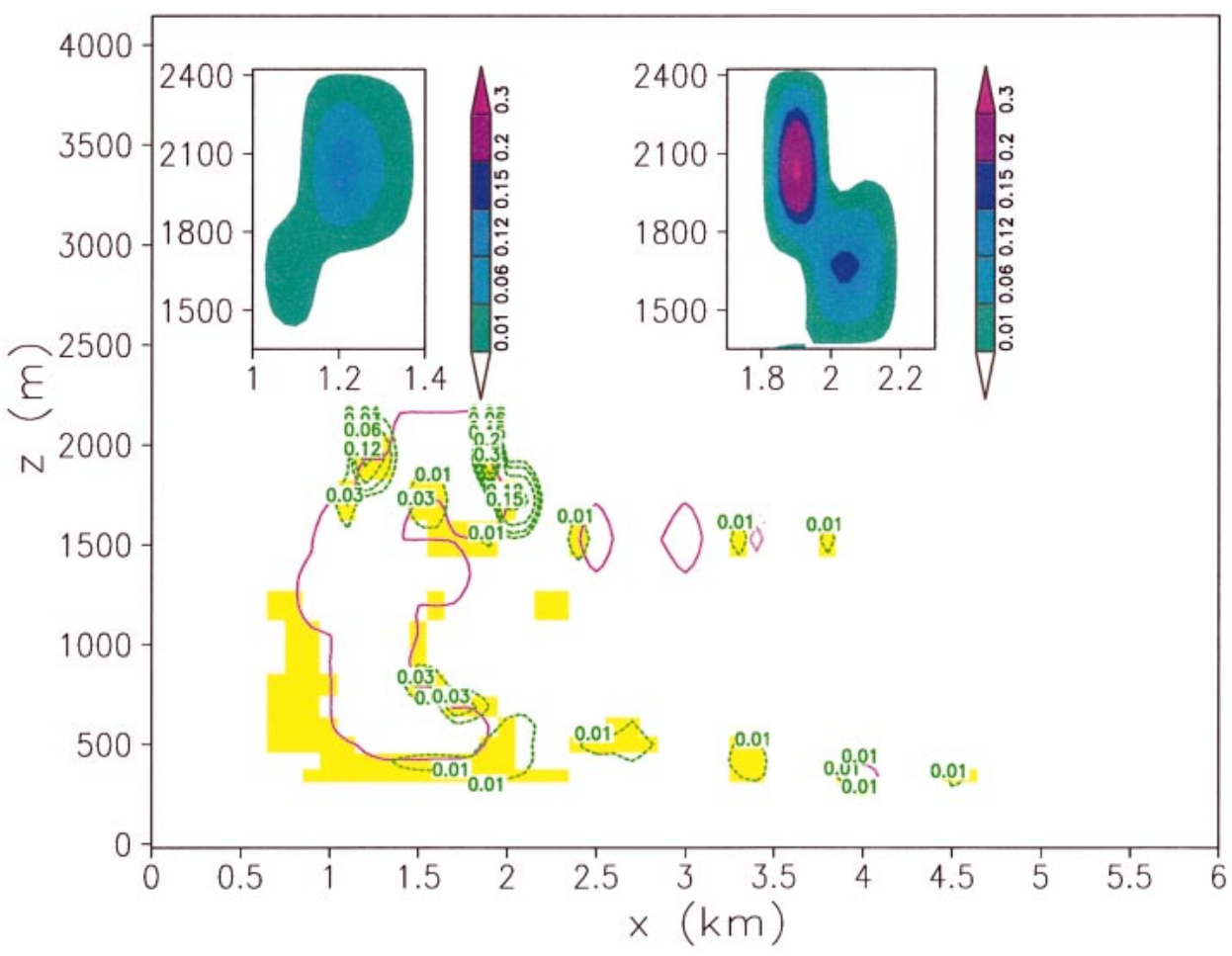

FIG. 16. Increase of the atmospheric heating rate in the presence of a cloud halo over that in the absence of a halo for the simulation shown in Fig. 11. Contour lines (green dashed) are 0.01, 0.03, 0.06, 0.12, 0.15, 0.2 , and $0.3 \mathrm{~K} \mathrm{~h}^{-1}$. The LWC contour line (purple solid) of $0.01 \mathrm{~g} \mathrm{~m}^{-3}$ is the cloud, and shaded regions (yellow) are the halo. Two shaded contour plots provide an expanded view of the enhanced heating rate near the cloud top. 
absorption over that in the absence of a halo. However, the increased absorption is only $0.63 \mathrm{~W} \mathrm{~m}^{-2}(0.6 \%)$ when averaged over the simulated cloud lifetime. This represents a small fraction of the $6 \%$ discrepancy between models and observations reported by Arking (1999) and others and commonly referred to as anomalous cloud absorption. The spatial distribution of the halo radiative effect is largest near cloud top, which, in addition to the humidity halo, results in conditions favorable to homogenous nucleation.

Acknowledgments. This work was supported by National Science Foundation Grants ATM-9907010 and ATM-9910744. This work was also supported in part by the Office of Naval Research. The authors wish to acknowledge Dr. William C. Conant for helpful comments. We also thank anonymous reviewers for their valuable comments on this work.

\section{REFERENCES}

Ackerman, B., 1958: Turbulence around tropical cumuli. J. Meteor., 15, 69-74.

Arking, A., 1999: The influence of clouds and water vapor on atmospheric absorption. Geophys. Res. Lett., 26, 2729-2732.

Austin, G. R., R. M. Rauber, H. T. Ochs III, and L. J. Miller, 1996: Trade-wind clouds and Hawaiian rainbands. Mon. Wea. Rev., 124, 2126-2151.

Bretherton, C. S., and P. K. Smolarkiewicz, 1989: Gravity waves, compensating subsidence and detrainment around cumulus clouds. J. Atmos. Sci., 46, 740-759.

Clarke, A. D., and V. N. Kapustin, 2002: A Pacific aerosol survey. Part I: A decade of data on particle production, transport, evolution, and mixing in the troposphere. J. Atmos. Sci., 59, 363382.

Collins, D. R., R. C. Flagan, and J. H. Seinfeld, 2002: Improved inversion of scanning DMA data. Aerosol. Sci. Technol., 36, 1-9.

Conant, W. C., A. M. Vogelmann, and V. Ramanathan, 1998: The unexplained solar absorption and atmospheric $\mathrm{H}_{2} \mathrm{O}$ : A direct test using clear-sky data. Tellus, 50, 525-533.

Evans, K. F., 1993: Two-dimensional radiative transfer in cloudy atmospheres: The spherical harmonic spatial grid method. J. Atmos. Sci., 50, 3111-3124.

_ - 1998: The spherical harmonic discrete ordinate method for three-dimensional atmospheric radiative transfer. J. Atmos. Sci., $\mathbf{5 5}, 429-446$.

Fu, Q., and K. N. Liou, 1992: On the correlated $k$-distribution method for radiative transfer in nonhomogeneous atmospheres. J. Atmos. Sci., 49, 2139-2156.

Hobbs, P. V., and L. F. Radke, 1992: Reply. J. Atmos. Sci., 49, 15161517.

Hoppel, W. A., G. M. Frick, and J. W. Fitzgerald, 1996: Deducing droplet concentration and supersaturation in marine boundary layer clouds from surface aerosol measurements. J. Geophys. Res., 101, $26553-26565$.

Jenkins, F., and H. White, 1957: Fundamentals of Optics. McGraw Hill, 637 pp.

Jiang, H., and W. R. Cotton, 2000: Large eddy simulation of shallow cumulus convection during BOMEX: Sensitivity to microphysics and radiation. J. Atmos. Sci., 57, 582-594.

Kaufman, V., and B. Edlen, 1974: Reference wavelengths from atomic spectra in the range $15 \AA$ to $25000 \AA$. J. Phys. Chem. Ref. Data, 3, 825-896.

Kebabian, P. L., cited 1998: Optical monitor for water vapor concentration. U.S. Patent 5,760,895. [Available online at http:// patft.uspto.gov/netahtm1/srchnum.htm.]
, T. Berkoff, and A. Freedman, 1998: Water vapour sensing using polarization selection of a Zeeman-split argon discharge lamp emission line. Meas. Sci. Technol., 9, 1793-1796.

— C. C. Kolb, and A. Freedman, 2002: Spectroscopic water vapor sensor for rapid response measurements of humidity in the troposphere. J. Geophys. Res., 107, 4670, doi:10.1029/2001JD002003.

Kerminen, V.-M., and A. S. Wexler, 1994: Particle formation due to $\mathrm{SO}_{2}$ oxidation and high relative humidity in the remote marine boundary layer. J. Geophys. Res., 99, 25 607-25 614.

Kollias, P., B. A. Albrecht, R. Lhermitte, and A. Savtchenko, 2001: Radar observations of updrafts, downdrafts, and turbulence in fair-weather cumuli. J. Atmos. Sci., 58, 1750-1766.

Lawson, R. P., and W. A. Cooper, 1990: Performance of some airborne thermometers in clouds. J. Atmos. Oceanic Technol., 7, 480494.

Liu, Y. G., and P. H. Daum, 2000: The effect of refractive index on size distributions and light scattering coefficients derived from optical particle counters. J. Aerosol Sci., 31, 945-957.

Lu, M.-L., R. A. McClatchey, and J. H. Seinfeld, 2002: Cloud halos: Numerical simulation of dynamical structure and radiative impact. J. Appl. Meteor, 41, 832-848.

Malkus, J. S., 1949: Effects of wind shear on some aspects of convection. Trans. Amer. Geophys. Union, 30, 19-25.

Marshak, A., A. Davis, W. Wiscombe, W. Ridgway, and R. Cahalan, 1998: Biases in shortwave column absorption in the presence of fractal clouds. J. Climate, 11, 431-446.

McManus, J. B., P. L. Kebabian, and M. Zahniser, 1995: Astigmatic mirror multipass absorption cell for long path length spectroscopy. Appl. Opt., 34, 3336-3338.

McNider, R. T., and F. J. Kopp, 1990: Specification of the scale and magnitude of thermals used to initiate convection in cloud models. J. Appl. Meteor., 29, 99-104.

Moore, C., 1971: Atomic energy levels. NBS Circular 467, U.S. Government Printing Office, $309 \mathrm{pp}$.

Murray, F. W., 1971: Humidity augmentation as the initial pulse in a numerical cloud model. Mon. Wea. Rev., 99, 37-48.

Perry, K. D., and P. V. Hobbs, 1994: Further evidence for particle nucleation in clear air adjacent to marine cumulus clouds. $J$. Geophy. Res., 99, 22 803-22 818.

_ 1996: Influences of isolated cumulus clouds on the humidity of their surroundings. J. Atmos. Sci., 53, 159-174.

Pielke, R. A., and Coauthors, 1992: A comprehensive meteorological modeling system-RAMS. Meteor. Atmos. Phys., 49, 69-91.

Platt, C. M. R., and D. J. Gambling, 1971: Laser radar reflexions and downward infrared flux enhancement near small cumulus. $\mathrm{Na}$ ture, 232, 182-185.

Radke, L. F., and P. V. Hobbs, 1991: Humidity and particle fields around some small cumulus clouds. J. Atmos. Sci., 48, 11901193.

Raes, F., R. Van Dingenen, E. Vignati, J. Wilson, J. P. Putaud, J. H. Seinfeld, and P. Adams, 2000: Formation and cycling of aerosols in the global troposphere. Atmos. Environ., 34, 4215-4240.

Raga, G. B., J. B. Jensen, and M. B. Baker, 1990: Characteristics of cumulus band clouds off the coast of Hawaii. J. Atmos. Sci., 47, 338-355.

Raymond, D. J., and A. M. Blyth, 1986: A stochastic mixing model for nonprecipitating cumulus clouds. J. Atmos. Sci., 43, 27082718.

_, R. Solomon, and A. M. Blyth, 1991: Mass fluxes in New Mexico mountain thunderstorm from radar and aircraft measurements. Quart. J. Roy. Meteor. Soc., 117, 587-621.

Rothman, L. S., and Coauthors, 1998: The HITRAN molecular spectroscopic database and HAWKS (HITRAN atmospheric workstation): 1996 edition. J. Quant. Spectrosc. Radiat. Transfer, 60, 665-710.

Steiner, J. T., 1973: A three-dimensional model of cumulus cloud development. J. Atmos. Sci., 30, 414-435.

Stevens, B., and Coauthors, 2001: Simulations of trade wind cumuli under a strong inversion. J. Atmos. Sci., 58, 1870-1891. 
Taylor, G. R., and M. B. Baker, 1991: Entrainment and detrainment in cumulus clouds. J. Atmos. Sci., 48, 112-121.

Telford, J. W., and P. B. Wagner, 1980: The dynamical and liquid water structure of the small cumulus as determined from its environment. Pure Appl. Geophys., 118, 935-952.

Vaillancourt, P. A., M. K. Yau, and W. W. Grabowski, 1997: Upshear and downshear evolution of cloud structure and spectral properties. J. Atmos. Sci., 54, 1203-1217.

Vogelmann, A. M., V. Ramanathan, W. C. Conant, and W. E. Hunter, 1998: Observational constraints on non-Lorentzian continuum effects in the near-infrared solar spectrum using ARM ARESE data. J. Quant. Spectrosc. Radiat. Transfer, 60, 231-246.
Walko, R. L., W. R. Cotton, M. P. Meyers, and J. Y. Harrington, 1995 : New RAMS cloud microphysics parameterization. Part I: The single-moment scheme. Atmos. Res., 38, 29-62.

Wang, S., and R. C. Flagan, 1990: Scanning electrical mobility spectrometer. Aerosol. Sci. Technol., 13, 230-240.

Warner, J., 1955: The water content of cumuliform cloud. Tellus, 7, 449-457.

_ 1977: Time variation of updraft and water content in small cumulus clouds. J. Atmos. Sci., 34, 1306-1312.

Weber, R. J., and Coauthors, 2001: Measurements of enhanced $\mathrm{H}_{2} \mathrm{SO}_{4}$ and 2-4 nm particles near a frontal cloud during the First Aerosol Characterization Experiment (ACE1). J. Geophy. Res., 106, 24 107-24 117. 